LIBRARY OF THE

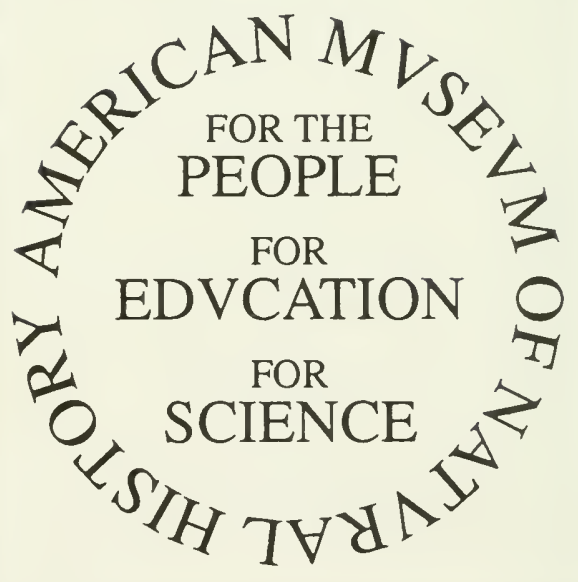







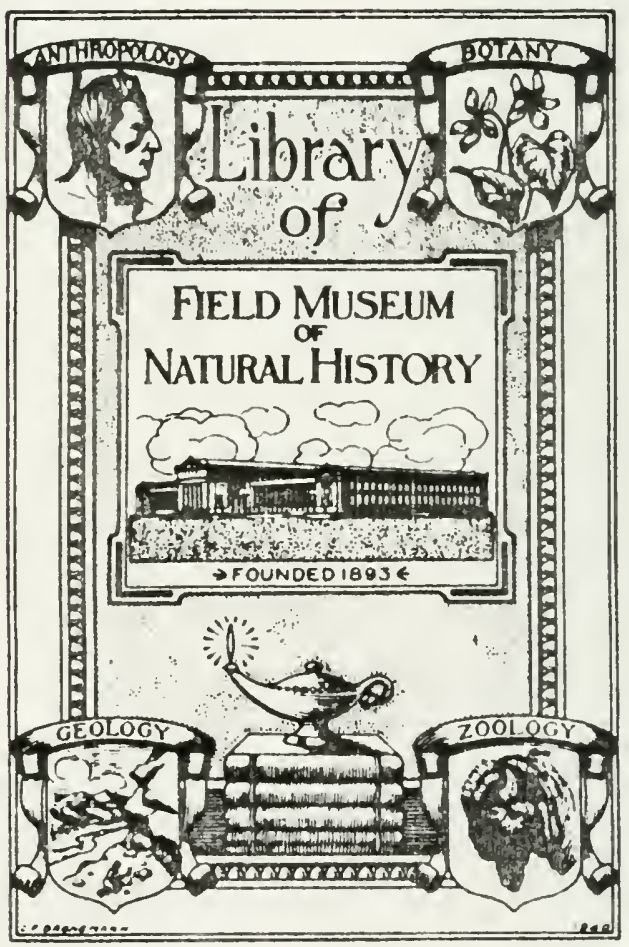




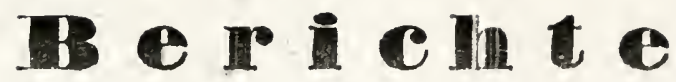

von der

Kön i glich en

\section{anatomischen Anstalt}

$\therefore \therefore$ K

Ne n t e r B e richt

von

\section{Feimrich Rathike,}

Professor der Zoologie und Anatomie.

Mit einem Beitrage zur vergleichenden Anatomie des $\Lambda$ ffen.

ron

Ernst Burdach, Prosector.

Königsberg, I 338 .

In Commission bet den Gebrudern Bornträger. 


$\phi$

801

$K 656$

no: 9

230314 


\section{The i c ht.}

$\boldsymbol{W}_{\text {ie früher, wurde auch seit der Zeit, da }}$ der letzte Bericht der anatomischen Anstalt gegeben worden war (im Juni 1835), in dieser alljährlich ein vollständiger Cursus der menschlichen Anatomie vorgetragen. Im Sommersemester wurden 0steologie und Syndesmologie von Herrn Prosektor E. Burdach, im Wintersemester Myologie und Neurologie von eben demselben, Splanchnologie und Angiologie aber von mir gelehrt. Vorlesungen über allgemeine Anatomie hielt jährlich Herr Professor C. F. Burdach. Ausserdem trug ich mit Benutzung der Sammlungen der Anstalt zweimal vergleichende Anatomie, wie auch Entwickelungsgeschichte des Menschen und der Thiere vor, der Prosektor aber im Sommer neben einigen chirurgischen Disciplinen die pathologische Anatomie. Die Secirübungen an menschlichen Leichen leitete während eines jeden Wintersemesters der Prosektor; zootomische Uebungen wurden unter meiner Anleitung regelmässig sowohl in Sommer, als auch in Winter angestellt. 

An den anthropotomischen Uebungen nahmen Theil: im Winter $1835 / 36$ 20 Präparanten (unter denen 10 Repetenten waren), im Winter $18^{36 / 3 \gamma} 31$ (10 Repetenten) und im Winter 18 ${ }^{3} / 38$ 32 (13 Repetenten). Leichname wurden an die Anstalt geliefert: im Jahr 1835 - 36 aus dem städtschen Krankenhause 8, aus dem Arbeitshause 8, aus dem Kreislazareth 5, aus dem medizinischen Klinikum 3, aus dem Löbenichtschen Hospital 3, und überdiess wurden ihr von den gerichtlichen Behörden überwiesen $\mathbf{3 6}$, also in Summa 63 Leichen. Im Jahr 1836 - 37 erhielt die Anstalt aus dem städtschen Krankenhause 14, aus dem Arbeitshause 4, aus dem Kreislazarethe 6, aus dem medizinischen Klinikum 2, von den Polizei- und Justizbehörden 25, in Summa 51 Leichen. In Jahr 1837 - 38 aus dem städtschen Krankenhause 24, aus dem Arbeitshause 7, aus dem medizinischén Klinikum 2, aus dem Löbenichtschen Hospitale 1, von Polizei- und Justirbehörden 29, in Summa 63. Von denjenigen Leichen jedoch, welche der Anstalt durch die Polizei- und Justizbehörden überwiesen worden waren, konnten viele, weil entweder Angehörige sich meldeten und ihre Auslieferung verlangten, oder in ihnen die Fäulniss zu weit vorgeschritten war, nicht zu 

anatomischen Arbeiten benutzt werden: andere mussten zu chirurgischen Operations - Uebungen abgegeben werden.

Was die Präparaten-Sammlungen der Anstalt anbelangt, so besassen dieselben im Jahre 1835 im Ganzen 2487 Nummern, und zwar die für normale menschliche Anatomie 992, für pathologische Anatomie 573 und für vergleichende Anatomic 922. - Zugekommen sind bis Ostern 1838 die nachbenannten 146 Präparate, so dass jetzt die anatomische Sammlung im Ganzen 2633 Nummern vählt, und zwar für normale menschliche Anatomie 1011, für pathologische Anatomic 605 und für Zootomie 1017.

I. Vom normalen menschlichen Körper.

1. Ein 'Theil des Rumpfes und Kopfes mit den Verzweigungen der Carotis und $\boldsymbol{\Lambda}$. mammaria interna. Getrocknetes Injectionspräparat.

2. $\Lambda$. und V. umbilicalis nebst Aorta und V. cuva, Leber, Nieren und Harnblase von einem Neugebornen. Getrocknetes Injectionsprïparat.

3. Schwangerer menschlicher Uterus mit Arterien und Venen. Getrocknetes Injectionspräparat. 

4. Die Venen des Kopfes und Rumpfes, vorzugsweise die der Wirbelsüule. Getrocknetes Injectionspriiparat.

5. Senkrechter Durchschnitt des Schädels mit $\boldsymbol{\Lambda}$. vertebralis und Carotis facialis und cerebralis. Getrocknetes Injectionspräparat.

6. A. carotis und sulbclavir mit ihren Verzweigungen an Mils, Brust und Oberarm. Getrocknetes Injectionsprïparat.

7. Das 7 te Hirnnervenpaar. In Spiritus.

8, 9 u. 10. Drei Präparate vom Ober- und Unterkiefer aus der Periode des Zahnwechsels, mit aufgebrochenem Canalis alveolaris und sichtbaren Milch- und bleibenden Zü̈hnen.

11. Senkrechter Ausschnitt cines männlichen Kopfes zur Demonstration -... des innern Baues der Nase. In Spiritus.

12. Horizontaler Ausschnitt eines männlichen Kopfes zur Demonstration des innèren Baues der Nase. In Spiritus.

13. Halswirbel und durchschnittener Kopf mit Muskeln zur Demonstration der Articulation des líopfes.

14. Normales menschliches $\mathrm{Ei}$ von der vierten Woche. Von Herrn Dr. Reichel geschenkt. 

15. Normaler menschlicher Embryo mit Eihüıten aus dem fünften Monate. Von Herrn Dr. Hirsch geschenkt.

16. Schädel eines Russen.) Vom Direktor ge17. Schädel eines Letten. schenkt.

18. Normaler, schöngeformter männlicher Schädel.

19. Männlicher Schädel mit starkhervorstehendem Hinterhauptsbeine.

NB. Die zur Ergänzung der durch den Gebrauch verdorbenen Prïparate gelieferten Arbeiten sind hier nicht mit angeführt. No. $1-13$ sind von dem Prosektor, No. 18 u. 19 von dem Anatomiediener angefertigt.

\section{Abnorme Bildung von Menschen} und Thieren.

1. Herz mit sehr weit offenstehendem Ductus arteriosus aus einem kurz nach der Geburt verstorbenen, durch Herrn Professor Dr. Heyn der Anstalt überwiesenen Kinde. Getrocknetes Injectionspräparat.

2. Ein Cor villosum. In Spiritus.

3. Herz mit sehr grosser Valvula Eustachii. In Spiritus.

4. Herz mit abnormer Vertheilung der Gefässstämme. In Spiritus. 

5. Magen mit Fungositäten, localer Erweichung und Durchlöcherung; unvollkommen injicirt. In Spiritus.

6. Verengter und sonst krankhafter Mastdarm. In Spiritus.

7. Oberarm eines Mannes mit einem pilzförmigen Knochenauswuchse, welcher sich mit einer Synovialkapsel umgeben in dem M. deltoideus befand.

8. Kniescheibe mit geheiltem Querbruche.

9. Weiblicher Oberschenkel mit schuppenförmigen Exostosen.

10. Oberschenkel mit Caries.

11. Tibia mit Caries.

12. Fibula mit Caries.

13. Clavicula mit geheilten Bruche und wucherndem Callus.

14. 'Tibia mit schiefgeheiltem Bruche.

15. Weiblicher Arm mit sehr verkürztem und verkrüppeltem Vorderarme.

16. An dem hinteren Bogen nicht geschlossener Atlas von einem Manne.

17. Doppelherz und Luftröhren mit Nerven und Muskeln von einem zweiköpfigen Füllen. In Spiritus.

18. Brust- und Hals -Wirbel mit Rückenmark von demselben. In Spiritus. 

19. Eine Schlinge vom Dünndarm eingeklemmt, in einem Loche des Mesenteriums. Von Herrn Dr. Graf geschenkt.

20. Fungositäten des Magens

21. Scirhositäten des Magens Professor Di. und der Speiseröhre

22. Blasenmole

Dietz geschenkt.

23. Fungus medallaris am Colon einer Frau. Vom Herrn Medizinalratlr v. Treyden geschenkt.

24. Káalbsschädel mit Verkümmerung der linken Orbita.

25. Doppelmissgeburt vom Schaafe. Vom Herrn Prediger Löffler geschenkt.

26. Dergl. Vom Hrn. Dr. Schaper geschenkt.

27. Dergl. Angekauft.

28. Cyclopische Lammsmissgeburt.

29. Rudiment vom Schädel des kopflosen Lamımes, welches vom Herrn Dr. Vogelgesang beschrieben worden ist.

30. Rumpf von demselben.

31. Menschlicher Hemicephalus. Vom Herm Dr. Schaper geschenkt.

32. Menschlicher Embryo mit Wolfsrachen und Verunstaltung der obern Extremitäten. Vom Herrn Dr. Koch geschenkt.

No. I - 19 sind von dem Prosektor priiparirt, und grösstentheils den zul den Secirübungen gestellten Leichnumen entuommen. 

III. Von Normalen 'Thierkörperil.

1. Skelet von Ursus Arctos.

2. $, \quad, \quad$ maritimus.

3. $"$ "Viverra Genetta.

4. $"$ "Hyaena striata.

5. $"$, einem grossen Jagdhunde.

6. $" \quad$ "Dasypus Peba.

7. $"$, Meles Taxus.

8. , , , Simia Mormon.

9. $", \quad "$ cynocephala.

10. " " Hapale Jacchus.

11.,$\quad$ 'Tamias striata.

12. $"$ Pteropus marginatus.

13. " Haliaeus Carbo.

14. $"$, Ara (Psittacus) Ararauna.

15. $"$, Picus martius.

16. $"$ "Procellaria capensis.

17. $"$ Python 'Tigris.

18. $"$, Pipa verrucosa.

19. " "Tetrodon ....

20. Schädel von Antilope lunata mas.

21. $", \quad, \quad$ fem.

22. " " Cervus Dama fem.

23. $, \quad, \quad, \quad \Lambda \times i s$ fem.

24., Phoca cristata.

25. $"$, Struthio Rhea.

26. $"$ "Phoenicopterus ruber. 

27. Schädel von Ramphastos .....

28. " " Xiphias gladius.

29. Schädel mit seinen Muskeln von Hyaena striata in Wachs boussirt.

30. Becken von Halichorus (Phoca) griseus.

31. Muskeln der vordern und hintern Extremität von Simia Cynomolgos (getrocknet).

32. Knochen und Bänder der vordern und hintern Extremität von Simia Sylvanus (in Spiritus).

33. Muskeln des Afters und der männlichen Geschlechtstheile von demselben (in Spiritus).

34. Muskeln des Flügels und Beines von Strix Bubo (getrocknet).

35. Muskeln und Nerven der vordern Extremitait von Chelonia Mydas (in spiritus).

36. Muskeln und Nerven der hintern Extremität von demselben (in Spiritus).

37. Gehirn derselben (in Spiritus).

38. $"$ von Simia Mormon (in Spiritus).

39. Auge von Bos Urus (in Spiritus).

40. $" \quad$ Meles Taxus (in Spiritus).

41. " "Halychorus griseus (in Spiritus).

42. $" \quad$ Strix Bubo (in Spiritus).

43. Ḱnochenkapsel aus der Sklerotika von Xiphias Gladius. 

44. Kopf mit auspräparirten Speicheldrüsen und Zungenmuskeln von Picus martius (in Spiritus).

45. Ein gleiches Präparat von Yunx torquilla (in Spiritus).

46. Verdauungswerkzeuge von Dasypus Peba (in Spiritus).

47. Verdauungswerkzeuge von Hapale Jacchus (in Spiritus).

48. Verdauungswerkreuge von Simia capucina (in Spiritus).

49. Verdauungswerkzeuge von Crocodilus palpebrosus (in Spiritus).

50. Verdauungswerkzeuge von Chelonia Mydas (in Spiritus).

51. Verdauungswerkzeuge von Pipa verrucosa (in Spiritus).

52. Verdauungswerkzeuge von Cyclopterus Lumpus (in Spiritus).

53. Verdauungswerkzeuge von Echeneis Remora (in Spiritus).

54. Magen von Halichoerus griseus (getrocknet).

55. Blinddarm von 'Tamias striata (in Spiritus).

56. Speiseröhre und Magen von Haliaeus Carbo (injicirt und getrocknet.) 
57. Athmungswerkzeuge, Zunge und Herz von Simia capucina (in Spiritus).

58. Athmungswerkzeuge, Zunge und Herz von Simia cynomolgus (in Spiritus).

59. Athmungswerkzeuge, Zunge und Her\% von Hapale Jacchus (in Spiritus).

60. Athmungswerkzeuge, Zunge und Herz von Dusypus Peba (in Spiritus).

61. Athmungswerkzeuge, Zunge und Herz von Crocodilus palpebrosus (in Spiritus).

62. Athmungswerkzeuge von Pipa verrucosa (in Spiritus).

63. Athmungswerkeuge von Chelonia Mydas (in Spiritus).

64. Athmungswerkzeuge von Emys europaea (in Spiritus).

65. Kehlkopf von Bos Urus (in Spiritus).

66. $\quad "$ Ursus Arctos (in Spiritus).

67. $", \quad$ Simia cynocephala (in Spirit.)

68. Kehlkopf und Luftröhre von Hyaena striata (in Spiritus).

69. Kehlkopf und Luftröhre von Halichoerus griseus (in Spiritus).

70. Kehlkopf und Luftröhre von Ciconia alba (getrocknet).

71. Kehlkopf und Luftröhre von Haliaeus Carbo (getrocknet). 

72. Weibliche Geschlechtswerkzeuge von Dasypus Peba (in Spiritus).

73. Weibliche Geschlechtswerkzeuge von Erinaceus curopaeus (in Spiritus).

74. Ruthenknochen von Halichoerus griseus.

75. Herz mit den Gefässstämmen von Lepus timidus (injicirt und getrocknet).

\%6. Herz mit den Gefässstämmen von Strix Bubo (injicirt und getrocknet).

77. Herz mit den Gefäissstämmen von Hàliacus Carbo (injicirt und getrocknet).

78. Herz mit den Gefässstämmen von Chelonia Mydas (injicirt in Spiritus).

79. Nerven und Arterienpräparat von Simia Sylvanus (in Spiritus).

80. Arterien des Rumpfes und Kopfes von demselben

81. Venen desKopfes v. einem Pferdefötus.

82. $\quad \% \quad \% \quad \%$

83. $\quad \%$ "

84. 9 \% 9

85. $9,9,9$

86. 9 9 $9, \quad$ Colymbus gla-

87. 9 9 99 cialis.

Strix Bubo.

Picus martius.

"major. Colymbus arcticus. Coluber Natrix. 
88. Venen des Kopfes von Gadus Callarias.

89. Venen des Kopfes und Rumpfes von Perca fuviatilis.

90. Venen des Kopfes und Rumpfes von Mus decumanus.

91. Venen des Rumpfes von einem Pferdefötus.

92. Venen des Rumpfes von Canis familiaris.

93. Hintere Hohlader und Pfortader von Strix Bubo.

94. Moschusdrüsen von Crocodilus palpebrosis. 95. Schwanzdrüsen von Coluber Natrix.

Die Präparate No. 31 - 35, 55, 62, 66, 70, 74, 76, 77, 81, 91 und 92 sind von dem Prosektor, die übrigen Prüparate weicher Gebilde zum Theil von mir, zum Theil bei den zootomischen Uebungen von Studirenden angefertigt worden. Die Skelette No. 2, 3, 12 und 17 hat der Conservator des zoologischen Museums, dic übrigen der Anatomiediener angefertigt.

Unter den Herren, welche der Anstalt Geschenke gemacht haben, verdient besonders Prof. Dr. Hayn dafür Dank, dass er derselben einige in der unter seiner Leitung stehenden Ent- 

bindungsanstalt verstorbene ueugeborne Kinder überlassen hat.

Die Bibliothek der anatom. Anstalt hat seit 1835, ausser den Fortset\%ungen der in ihr schon vorhandenen grössern Werke, einen Zuwachs von 151 Werken erhalten, und besitzt gegenwärtig deren im Ganzen 1708.

Was endlich die Bestrebungen anbelangt, mit Hülfe der in der Anstalt vorhandenen Mittel den Wissenschaften durch neue Schriften förderlich zu sein, so erschien seit dem letzten Berichte von mir: eine Abhandlung über den Bau und die Entwickelung des Venensystems der Wirbelthiere (als Beigabe zu dem dritten Jahresberichte über das naturwissenschaftliche Seminar zu Königsberg);

vom Prosektor: Beitrag zur mikroskopischen Anatomie der Nerven. Königsberg 1837 bei Borntäger.

vom Dr. Vogelgesang: Dissertatio de perocephalo aprosopo foetus ovini.

Königsberg im Juni 1838. 


\section{I e itra}

zur vergleichenden Anatomie der Afren.

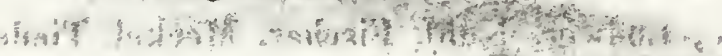

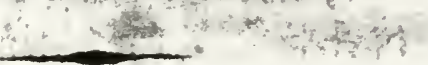

Dasi dic Aehnlichkeit des innern und üussern Baues der Affen mit dem des. Menschen lange Zeit bedeutend überschätzt worden ist, haben Tyson und Camper zuerst dargethan, und alle folgenden Untersuchungen immer mehr und pehr ins licht gessiblt to Wieviel man aber auch dem Affen von der ihm früher beigelegten Mensehenähnlichkeit bereits entrissen hat, und noch entreissen möge, gewisa wird ter jimmer nächst dem Menschen die erste Stufe in der Reihe der Thierwelt behaupten. Wenn es nun, wie dies in unsern Tagen so schr anerkannt wird, höchst interessant ist, den Ursprüngen aller organischen Billung in der Entwioklung des Individilums oder der ganzen Thierreihe nachxispüren; so ist es gewiss auch nicht miniler interessant, den morphologisehen Bau der am hö̈chsten organisitten Thierklasse zu untersuchen, iond dadurch zugleich die Gränze zwischen idex rein thiorischen und der mensclitichen 

Bildung näher ins Ange zu fassen. Hiernach muss es uns wohl auffallend sein, dass bis jetzt noch keine vollständige Bearbeitung der vergleichenilen Anatomie des Affen erschienen ist, während wir doch dergleichen nicht nur von anileren Säugethieren, sonlern auch von vielen weit niedriger organisirten Thieren besitzen. So schätzenswerth auch die Arbeiten über den Affenivon Tyson, Camper, Josephi, Vicq d'Azyr, Iudwig, Kuhl, Fischer, Meckel, Tiedemann, Cuvier u. A. mosind, immer bleiben sie noch ungenügend, da sic theils das Ganze nur oberflichlich behanideln, theils nur cin besondres System des Körperg, oder eine einzelne Affonspeciest zún Gegenstand nohmen aür eine von der Zukunft noch zu erwartende vollstindige Bearbeitudg dor bergleichenden Anatomie des Affen erlaube ich mir in ler folgenden Abhandlung einen kleinen Beitrag zy liefern, indem ich eine vergleichende Darstellung des Muskelsystems der bei uns an häufigsten vorkommenden Affenarten versuche. Die Güte des Herm Direktors unsres zoologisehen, zootomiselien sunt anatomisehen Museums hat mir die Gelegenheit verschafft, , diesem Zwecke einige Exemplare von Cercopithecus, Cynocephalus und Inuus der Zergliederung su unterwerfen. Obgleich mun meine gegen. wärtige Mittheilung sich auf die genannten drei Affenarten beschränken muss, so hoffe ich doch, dass dieselbe nicht ganz werthlos erscheinen werde, Theils die hei diesen Arten gefundene grosse Ueber- 

einstimunug in der Bildung mich anch nur geringe Abweichungen bei andern Arten vernuthen lisst, solche Abweichungen' aber jedenfalls leichter aufyefasstiwerden können, wenn nur exst ein allgemeiner Typus der Bildung festgestellt ist; andern Theils aber unter den drei genannten Arten wenigstens der Mägot mir zu den Affen zu gehören scheint, deren Bildung dev mensehlichon am nüchsten koumt, denn von den Affen der alten Welt móchte selbst der fri s. $_{\text {, }}$ her fïr einen wilden Menschen gehaltene OrangUtang ihm kaum in wesentlichen Stücken, z. B. der Schadelbildung, den Rang streitig machen, und dass alle Affenarten der neuen Welt mehr die rein thierische Bildung zeigen, ist $\mathrm{j}_{\mathrm{i}}$ im Allgemeinen schon früher anerkannt, neuerdings aber durch Ogillyy in oin nooh helleres Liohe gestelt, 1 indein haoh diesem then satmmtlich der Besitz cines entgegenstellbaren Daumens abzusprechen ist. Dass ich gerade das Muskelsystem zum Gegenstand meiner Untersuchung gemacht habe, hat seinen Grund einmal darin, dass das Knochensystem der Affen bereit vielfach und voltstindig untersucht worden ist, diesem aber sich des der Muskeln am passendsten ansehliesst; ferner uber, und ganz besonders darin, dass auf der Ein richtung der Muskeln, welche doch so hiufig von den Zootomen als Nebensache behandelt werden, hauptsächlioh die körperlichen Vorzüge des Menschen voridon Thieron beruhen, wie dies weiter unten besprochen werden wird. 

externus fast ganz beleckt, nach vornabiürts, um mit jenem verschmolzen zum Mundwinkel zou gelangenti Der garize Muskel hat in seinen Verlaufe eine Richtung schräg von oben und hinten nach unten und: vorne, undl lässt sich in Betreft seiner Endigung in drel Partieen theilen. Die oberste oder vorderste Partie, grössten Theils von dem Subcutaneús faciei gebildet, verliert sich an dem Mundwinkel und der Oberlippe, sich mit dem Orbicularis oris verbindend, und sendet auch einzelne Bündel nach der Gegend des Auges und zur Ohrinuschel hin; die mittlere, schwächste Partie löst sieh in cinzelne Faserbíndel auf und verliert sich auf den Backentaschen; endlich die breiteste, hinterste und unterste Partie gelangt, von Brust, Schulter und Rücken komuiend, and dor allgemeinen Riehtung folgend, mit einem Theile über den Winkel des Unterkiefers hin zum Mundwinkel ihrer Seite, mit dem anderen Theile aber triftit sie an der untern Fläche des Balses, ctwa vom dritten Hảrswirbel an, auf den gleichnamigen Muskel der andern Seite; durchkreuzt diesen, und gelangt endlich zu der Un' terkieferhälfte der entgegengesetzten Seite und zu dem Kinne, woselbst sie mit allen der Unterlippe angehörigen Muskeln zu eincr Masse verschmolzen ist. In Folge jener Durchkreuzung wird der Raum an der untern Fläche des Halses und Kopfes vom vierten Hale wirbel bis zum Kinne mit einer doppelten Muskelschicht bedeckt, deren Verflechtung so innig ist, dass stellweise bald die Faserbündel welche der einen, 



\section{$-7$}

bald die welehe der andern Seite urs!rünglich angebören, oberdisohlioher liegen. Endlich ist noch eine, nicht ganx schwache Muskełpartie zu erwihinen, wel- the aus der Durchkreuzung hervorgehend an' der ihreni Ersprunge entgegengesetzten Seice des Gesichts vebun lem Mundwinkel vorbei in die Höhe steigt, un sich in der unterhalb des Auges liegenden Muskulatur zu verlieren.

Bei Cynocophalu schien mir dieser Muskel am stiirksten, bei Inuus am wenigsten ontwiokelt towicivis 2. mo oboutaneus abdominis s, maximus hat eine der des Latissimus dorsi nicht ganz unähnliche Gestalt. Er nimmt seinen Ursprung ungefahr auf der Halfte der Längenausilehnung des Darmbeins in einer Breite; dass sein oberster Ursprungazipfel bis in die Sehnenhout des Schwanzes, der ontorst Wib tur Lieistengogend roicht; von hiernus gehtersuingunichst parallel mit der Wirlielsulute, an weleher en dem deriandensin Seite bis auf wenige Linien bennchbart ist; gerade nach vorn; sowie er aher bis zu den Rippen gelangt ist, fangen teine Fasern an zu convergiren; und es treten neue Muakelbúndel hinzu, welche von der Wirlselsäule entspringend theils schräg nach vorn, theils senkreeht, theils endlich schräg nach hinten abwärts laufen, um mit den übrigen vereinigt einen von der Brustwand abtretenden Muskelbauch zu bilden, welcher endlich mittelst einer Sehne am Oberarm endet. Auf diese Art bildet der ganze Muskel eine 

Decke für die obere und seitliche Flächendes Bau. ches und der Brust bis etwa zur Mitte des Schulterblattes hin, sammelt dann seine Fasern, von denen nur wenige gesonilert in der Haut endigen, $\mathrm{zu}$ einem. Mușelbauche, welcher nicht mehr den Charak. ter eines Hautmuskels seigt, und geht endlich: in eine dünne Sehne, über, welche, an der innern Seite des Latissimus dorsi liegend, mit diesem zun oberarm gelangty, dasclbst aber, sich schrigg über den sulcus intertubercularis ausspannend, ebensowohl an dem tuberculum minus als an der spina tuberculi majoris angeheftet ist.

II Muskelndes Schadels und des Gesichts

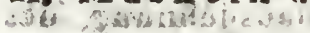

Das ganze Schädelgewölbe ist mit einer, wenn auch dünnen, Muskelschicht bedeckt, zu deren Bildung ein Stirnnuskel, ein Ilinterhauptsmuskel und die das äussere. Ohr bewegenden Muskeln zusammentreten; beim Pavian fand ich eine nur einen halben Zoll grosse Stelle auf der Mitte des Scheitels, au welcher die galea, aponeurotica unbedeckt zum Vorschein kam, beim Magot und der Meerkatze auch diese nicht einmal.

1. m. frontalis erscheint unpaarig, nimmt seinen IJsprung von der Nasenwurzel und dem ganzen obern Augenhöhlenrande, und geht mit seinem mittleren Theile in gerader Richtung nach hintenxu in die Höhe, mit seinen beiderseitigen assersten Theilen aber schriig nach aussen zur Ohrmuschel, 

so dass dicse letzteren als $m m$, $n$ t trahentes a u ri c u l a e ansusehen sind.

2. Die beiderseitigen mm. attollentes auri- ula bilden, inlent sio längs der Sagittalnath zusommentreten, gemeinschaftlich ein gleichschenkliges Dreieck auf der hintern und obern Fliche des Schidels, dessen mittlerer Winkel nach tuten und hinten gerichtet an dem Nacken etwa bis zum ersten Halswirbel reicht, Jessen seitliche Winkel ferner sich ail der dem Schadel zugekehrten Fitche ter beiderteitigen Ohrmuscheln anheften, und dessen Basis endlich auf der Mitte des Scheitels zu suchen wäre, woselbst aber die Fasern des Muskels unmittelbar in die des m. frontalis übergehen.

3. m, occipitalis kommt erst zum Vorschein, nachdem der vorgenannte Muskel entfernt ist; cr entspringt rom mittleren Theile des starkhervortretenden Hinterhauptskanmes, welcher theils dem Scheitelrande des Hinterhauptsbeins, theils den Zitzentheile des Schläfenbeins angehört, und geht, lang uud schmal, gerade nach vora, un sich von untenher mit dem m. frontalis zu verbinden.

4. m. retrahens auriculae bestehtan jedem Ohre aus zwei Theilen, die aber bei ihrer Insertion

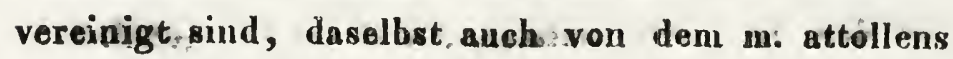
auriculse bedeckt werden. Sie entspringen von dem hintersten und untersten Theile der Ohrmuschel, gehen schräg nach inuen und hinten, und setzen 

sich neben den vorgennnnten Muskel nach aussen an die obere Fläche des Hinterhauptskammesan. 5. m, orbicularis palpobrarum untergcheidet sich dadurch sehr wesentlich von dem des Menschen, dass nur seine innere Lage, stratum internum, einea wirklichen Sphingter darstellt die Muskelfasern der dussern Lage dagegen nioht in sieh geschlossen ersoheinen, sondern nachiem sie mit ihrem Bauche den änssern, obern und innern Augenhöhltenrand umgeben halon, nit ihren beiden Enden yon dẹm untern Augenhöhlenrande aus gerade abwärts steigen, und sich in die Oberlippe einsenken. Wollten wir den Lauf dieser Lage verfolgen, so müssten wir annehmen, dass sie von ler Oberlippe, in der Breite vom Eckzahne bis zum zweiten Backzahne reiehend, entspringe, zu dem Joohbeine gehe, an dessen Stirntheile aufsteige, sich über den obern Augenhöhlenrand am Stirnbeine hinüberwölbe, lann lings der pirs frontalis des Oberkiefers neben dem inneru Augenwinkel vorbeigehe, und endlich an den Gesichtstheile desselben Knochens hinabsteige, ium sich wieder in die Oberlippe, vom Eckzahne bis zum zussern Schneillezahne, einzusenken.

6. Dicht an den aussern Rand des ebengenannten Mluskels schliesst sich ein Muskel an, welcher von dem Jochbeine entsteht, und am Mundwinkel in die Oberlippe eintritt, und sich als m: zy gomati cus major zu crkennen giebt; ein minor ist nicht vorhanden. 

7. Den Raum zwischen iden Augenlierlschliessern beider Seitemeirmehmendy und sehr innig mit den einander zugekehrten Ründern derselben verbunden, entspringt ein m. Levatorlabio operioris a laéque a a s i von dem Nasenfortsatze des Stirnbeins, und goht geraile alowhrts, un sich theils auf der'Nuse zu verlieren, theils nelsen derselben herabgehend in der Oberlippe zu endigen.

Auf diese Weise wirl auf der Gerichtsflache des Affen eine von dém einen Jochbeiné bis zum andern reichende Musketmasse gebildet, welche nur mit Miihe in die genannten Portionensu tremen ist, und mit fast ganz parallelen Fasern zur Oberlippe heralogeht. 8. Von der eben beschiebenen Muskelmasse bedeckt, und nur nach deren Wegnahme erkennbar, findet wich ein ron dem Oborkiefer tönga des Randes der apertura piriformis eutupringender Muskel; welcher horizontal nach aussen und etwas nach hinten absteigt, urid sich in "den Mundwinket verliest; indew er zugleich von der Seite her auf den mo jor aufstösst." Dieser Muskel stimmt hinsichts seiner Gestalt und seines Ursprunges mehr mit dem m. levator lalii proprids finsichts seiner Insertion mehr mit den m. levator anguli oris überein, unterscheidet sich aber'von beiden wesentlich durch die Richtung seiner Fasern.

31 9. Die für dic Bewegung der Untertippe hestininte Muskulatur des Kinnes wird hauptsächlich von dem schor beschriebenen Subcutaneus colli, der 

sje vom hintersten Ende des Jochbogens nur bis zur Mitte des .Unterkiefernstes reicht.

.. J5. mm, p torigoid deind stark, bilden alser nur eine nicht mit Sicherheit zu trennende Masse, und:haben, da die processus pterigoidei dem Unterkiefer sehr nahelliegen, einen nur kurzen Verlauf.

III. Muskeln an der vorderen und seit lichon Pluchoudes Halseq.

1. mo sternocleidomastoidens kommt fast ganz allein rom Brustbeine, und setzt sich breit unterhalb sler starken Hinterhauptsleiste, sow wit dieselbe der pars mastoilia des Schlïfenbeins angehört, fest, so dass er dem robenbesehriebenen Retrahens auriculae entgegentritt. Meokel hat bei Papio Sphinx eine kleino pars clavieuloris diesesos Muskels gefunden, welche sich an der Mitte des aussern Raniles der pars sternalis ansetzte, was ich aber nicht bestäti-

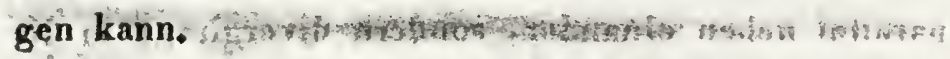

2. mm. scaleni, Es sind drei dergleichen vorhanden, von denen der hinterste der ansehnlichste ist. Derselbe igeht von den vier bis fünf olvern IIalswirbela an die zweite bis fünfte Rippe hinab, woselbst er sich mit dem absteigenden schiefen Bauchmuskel verbindet; der mittlere ist oben eng mit dem hintern verbunden, und reicht von den drei his vier untern Halawirbeln zur ersten Rippe; endlich der vondere ist mehr gesondert, und geht von dem dritten bis sechsten Halswirbel ebenfalls zur crsten 



\section{$-14-$}

Rippe. Der m.. scalenus medius kann ibrigens auch leicht für den posticus genommen werilen, da er weler ganz vor, inoch ganz hinter dem grössten, sondern nach innen von demselben liegt.

3.mm. Longissimus oolli, rectus capim tis anticus major, minorundateralis fraigen nichts von der menschlichen Bildung Abweichendes.

IV. Muskeln, welchedie am Halse und in der Mundhŏhle liegendon Organe

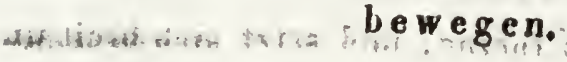

1. mm. sternohyoideus und sternothyreoidens gind in der. Nühe des Brustbeins sowohl untercinander, als mit denen der andern Seite zu einen Muskel verbunden, wad diese Verhinding ist durćh einen flechsigen Querstreifen unauflösslich gemacht. Sie entspringen sehr tief in der Brusthöhle. Die beiderseitigen mm, ternothyreoidei gehen nicht parallel neben einander, sondern divergirend in die Höhe, und heften sich auch schon an den untern Rand des Seitenstüekes der cartilago thyreoilea in. *his 2. mo moh yoide us hat keine Zwischensehne, und légt siehòin der Nähe des Zungenbeins ganz dicht an den $m$. stemohyoideus an, mítidem er gemeinschaftlich am Zungenbeinkörper inserirt.

3. Der dem menschlichen Hyothyre oideas entsprechende Muskel entspringtischon am untern Rande, da wo der $m$. sternothyreoideus inserirt, von der vordern Fläche der cartilago thyreoidea, 

und setzt sich nur tose mit seiner der I uftröhre sugewendeten Fläche ans os hyoideum an; mit dem grobsten Theilo sciner Fasern, "und namentlich mit allen, vile von vorno her sichtbar sind, geht er gerade in die Hähe, und senkt sich, nachdem ein rón der Mitte des Zungenbeins kónimender m: h y o glosa su shm getreten ist, in die Zunge ein, so diss or also eigentlich oinen m. th y reohyog los us danstellt Bei dom Pavian, nielit alier bei den anNern Affenarten, fand ich noch einen eigenen, sehr dianen mishothyreoilleus;' welcher vom vorigen beteekt vom oluetn Ranider des "Schililknorpels siom Zungenbeine ging.

4. m. digastricus steht nur in mittelbarer Verbindung mit dem Zungenbeine. Nachdem die Sehne seines hintern Bauches naimlich den m. stylohyoidens wchon sehr früh durchlohrt hat, geht sie chrag nach vorne und innen, um sich in der Mittellinie, etwa einen halben $Z$ oll vor dem Zungenbeine, mit der gleichnamigen Sehne der andern Seite zu vérbinden. Von dem ganzen, dem Kinne zugewendeten, vordern Rande dieser Sehne nimmt nun mit kurzen Sehnenfasern ein breiter vorderer Bauch seinen Ursprung, welcher sich an die ganze vordre Hăfte des Unterkiefers bis zur spina mentalis interna ansetzend init dem der andern Seite gemeinschaftlich fast den ganzen Raum zwischen den beiden Unterkeferhalften ausfültt. Bei Cercopithecus 



\section{$-16-$}

schien er sich nur an den Stylohyoideus anzulegen, nicht ihn eu durchbohren.

scis b.ims tyl ohy oideus setrt sich, seitlich auf die Insertion des m. sternohyoideus anftreffend; mit diesem ganz in der Mitte des Zungenbeinkörpers fests ㄷ. 6. m. m y loh y o id en wird von un tenher durch den Digastricus fast ganz bedeokt, er, wie aus ider Beschreibung jenes erhellt, nur in dem dreièckigen Raume vor dem Zungenbeine und hinter den sich verbindenden beiderseitigen sehensehnen des Digastricus frei liegt, woselbst er jedoch nuch noch yon einer dïnnen Aponeurose überzogen wird, welche von jenen Sehpen zum Zungenbeine hinübergespannt ist. Er inserirt theils an dem langs der Mittellinio hingehenden Sehnengtreifen, theils mit mehr Muskelfasern als beim Menschen unnittelbar an dem Zungenbeine, theils endlich noch mit eiper ansehnlichen Partie an der obern Flïche jener Mittelsehne des Digastricus.

7. m. geniohyoideus ist auffallend stark.

8. m. genioglossus reicht bei seinem Eintritte in die verhiltnissmässig lange Zunge sehr weit nach vorne.

9. m. styloglossus entspringt breit von einem sehnigen Bande, welehes ron dem processus styloideus zum Winkel des Unterkiefers geht. Er tritt, neben dem oben beschriebenen m. thyreohyoglossus nach aussen liegend, in die Zunge, und lasst sich, so wic jener, bis tief in die Substanz. 

hinein und bis fast zur Zungenspitze hin von dem Aenioglongus ganx getrennt verfolgen.

10. Da sich die genannten Zungennuskeln bis fast zur Rückenfluche der Zunge isolirt verfolgen liessen, kam mir kein eigentlicher m. lingualis zu tesieht." $-a+4$

11. m. stylopharyngeus befestigt sich im Vorbeigehen an das Ende des grossen Zungenbeinhorna.

12. An den Muskeln des Kehlkopfs finde ioh keino bedeutende Abweichung von der menschlichen Bildung; nurist der m, cric oth y reo id e u s bedeutend athicer, da die Beweglishkeit zwischen Ringund Schildknorpel bei dem Affen überhaupt grösser ist; auch serfullt derselbe deutlich in eine aussere und oine innere Portion Der m. cricoarytaenoidou poșticus bedeckt die ganze hintere Flïche des Ringknorpels, der lateralis ist dem menschlichen gleich; der m. thyreoarytaenoideus ist sehr stark; an dem m. arytaenoideus zeigen wioh hauptsăchlich nur Querfasern. Die Muskeln des Kehldeekels vermochte ich nicht deutlich wahrzunehmen.

13. Von Constriktorendes Phary nx finde ich: zu unterst einen sehr schmalen m. cricopharynge us, welcher von dem Seitentheile des Bogens des Ringknorpels entspringend etwas anfwarts um die hintre Wand des Schlundkopfes herungeht; 
darïber einen m. thyreopharyngeus, der von lem untern Horne und dor äusern Fliche dos Seitentheils des Schildknorpels, von dem Thyreohyoideus etwas bedleckt, seinen Ursprung nimmt, und aufwarts steigend mit seinem obern, in eine mittlere Spitze ausgehenden Theile den folgenden Muskel zum Theil deckt; noch höher einen m. hyopharyngeus; der von der äussern Fiăche des gressen Horns, woselbst er von dem als unmittelbare Fortsetrung des Thyreohyoideus erscheinenden Hyoglossus bedeckt ist, und von ihm verstärkt wird, entspringt, und sich, mit dem Stylopharyngeus vereinigt, so über den Pharynx ausbreitet, dass seine obern Fasern aufwärts, die mittleren horizontal, die untersten ctwas abwärts gerichtet sind; endlich einen m. constrictor supremus, welcher wie beim Menschen in einen m. pterygopharyngeus, glossophaxyngeus und mylopharyngeus xerfaillt.

14. Das Gaumensegel zu bewegen dient zunachst ein m. glossopalatinus, der dem menschlichen ahnlich ist; fermer ein m. pharyngopalatinus, der aber, so lange er mit der Schleimhaut bedeckt ist, gar nicht sichtbar ist, und von dem Gaumensegel aus sehr schräg nach hinten verlăuft; ferner ein m. tensor und levator palati mollis, welche nichts Bemerkcnswerthes zeigen, Einen m, azygos uvula konnte ich nicht entdecken. 

7., Muskeln apdem Nacken und Rücken.

1. m. cuenllaris ist wegen der Iange der spina scapulso verhältnissmässig breiter als beim Mensehen. Bei den von mir zergliederten Affen inserirt ex wueh an einem kleinen Theilc des Schlüsselbeins, was bei Capucina nach Meckel nicht der Fall sein 20ll. Mit soinem Kopfende setzt er sich breit an die untere Flikehe der queren Hinterhauptsleiste an, so dave er, nach aussen an den Sternocleidomastoideus stoswend, mit dissem ebenso die ganze untre Fuahe diener atarken Leiste einnimunt, wie deren -bere. Flihche van dems m. occipitalis und $m$. retrabens auriculao eingenommen wird; such ist er daselbat von dem attollens auriculne theilweise bedockt.

2. mo hassimu do rai bekount gar keine Ventikrkungtuipfol von den Rippen; dem Oberarme sieh nlbernd giebt er von seinem vordern Rande ein kleines Muskelbundel ab, wrelohes sieh mit dem Tores major verbindet, und mit diesern gemeinschaftlich endet, wàhrend er selbst etwas tiefer an der spina thareuli minoria inserirt; ferner schickt er, wie Heckel beschreibt, von seiner Sehne einen ansehnlichen Muskelbauch an den Lillenbogenknorren, der ganz von den übrigen Vorderarmstreakern getrennt int, indewaen möchte derselbe wohl besser als ein -igener. Mukkel zu betrachten sein, da er, mit eigenthilmalichen kurwen: Ursprungssehnen versehen, unter einern otumpfen Winkel von dem llatissimus alogeht. 

3. m. xhomboideus reicht vom sechsten Brustwirbel bis zum Hinterkopfe in die Höhe, und besteht aus zwei deutlich getrennten - P'heilen; der vordere entspringt an dem innern Winkel des Schulterblattes, woselbst or mit dem Levator scapulae eng verbunden ist, und geht, bei Inuus und Cynocephalus etwa einen Zoll breit; ans Hinterhauptsbein, - indemer sich dicht unter dem $m$. cucullaris an dic starke Querleiste ansetzt; der hintere, breitere Theil reicht zu den Dornfortsätzen gehend auch bis dioht ans.Hinterhaupt, indem er mit seinem vordersten spitzzulaufenden Ende dem $m$. attollens auriculae gerade entgegen tritt.

4. Lin dem Menschen nicht eigener Muskel, von Vicq d'Azyr m. acromio-basilairogenannt, entspringt, vom Cueullaris bedeckt von dem Aerómion bis fast zur Mitte der vordern Fläche der Schultergrilte, und setzt sich anden. Querfortsatz des Atlas an; den kleineren, dessen Meckel Erwahnung thut, und welcher vom Schlüsselbeine zur Haut des Hinterkopfes gehen soll, habe ich ntcht finden konnen; und wird derselbe wohl nur ein Bündel des CuculLaris sein.

5. m. levator capulac geht vom vordern Dritheil der basis scapulae zu den Querfortsützen aller Halswirbel. Sein vorderster, an: die drei ersten Halswirbel gehender. Theil ist etwas von' dem "hintern getrennt, weshalb Meckel und Cuvier den letztern zum m. serratus anticus major gerechnet haben; 

indessen ist eine Trennung zwischen dieser hintern Poŕtion des Levator scapulae und dem Serratus anticus major in der Nulie der ersten Rippe leiclit aufzufinden.

6. m. serratus posticus superior geht bei Cynocephalus an die sechs vordern, bei Inuus nur an die dritto bis sechste Rippe.

7. m. serratus posticus inferior gleicht dem menschlichen.

8. m. spleniuscapitis: ist sehr stark, entspringt von den Dornfortätzen bis zum vierten oder finften Brustwirbel hin, und setzt sich dick an die starke Querleiste "des Hinterhauptes; auch giebt er eine dunne Zacke an dén processus transversus des enten Halswirbels ab, welche wohl für cinen $m$. "plenius colli anzuiselien ist, dal dieser sonst ganz fohlen wirite.

9.m. sacrolumbalis reicht wie bei dem Menschen bis zun siebenten Halswirbct.

10. m. Iongissimus dorsi setyt sich mit sciuen uussern Zacken nicht nur an alle Rippen, sondern auch an die Querfortsịtze der sechs untern Hahmirbel Dieson Mnskel stellt zugleich den m. transversalis cervicis, nicht dea m. cervicalis descendens wie Meckel meint, dar, welcher sonst ganz fehlon würde.

11. mo cervicalis descendens, welchen Cuvier beim Affen verninst hat, kommt zu Gesicht, wenn man den Halstheil des vorgenannten Muskels 



\section{2}

vorsiohtig aufhebt. Er entspringt als ein sehr dünner Muskel von den drei vordern Rippen und geht mit seinen Sehnen, welche mit aenen des Longissimus verbunden sind, an die Querfortsätze des drit:ten bis echsten Halswirbels. क o the

12. m. trachelonastoideus ist nur dunn.

13. mm. biventercerviels und complexus siud unzertrennlich, und haben keine $Z$ wischensehnen; sie setzen sich an die unterhalb der starken Querleiste befindliche schwache Querlínie des Hinterhauptsbeins un.

14. mo o pin alis dorsi entepringt hinten deutlioh von der Sehnenhaut des m. longissimus dorsi und ist auch in seinem ganzen Verlaufo mit demselben durch äussere muskulöse Zacken verbunden.

15. mm. semispinalis cervicis et dorsi, und multifidus pina zeigen nichts von der menschlichen Bildung Abwcichendes,

16. Die kurzen hinteren Kopfmuskeln sind den menschlichen gleich; nur setwt bich der m. reotus capitis superior nit dem inferior ganx in gleichor Höhe; nämlich dicht über dem foramen magnum, aber nehr nach aussen ans Hinterhaupt an, so dass man den inferior ganż sêhen kann, ohne den superior entfernt zu haben; daher erscheint denn auch zwisclien deni $m$. rectus superior, abliquus superior und obliquus inferior kein so regelmässig dreieokiger Raum als bei dem Mensehen' 

14y 17. Die kleinen Muskeln, welche zwischen den einzclnen Wirbeln liegen, und die, welche die Rippen bowegen bieten nichts Bemerkenswerthes lar.

11. Muskeln an der vorderen Flache der Brast.

1. II. poctoralis major ist lang und schmal, entapringt vom ganzen Brustbeine und dem Uusternten Stornalende des Schlüsselbeins,'stösst mit dem der andern Seite auf der Mitte der Brust susammen, und geht hinten in die Aponeurose der Bauchmuakeln uber. Eine pars clavicularis kann man von der sternalis nicht deutlich unterscheiden, dagegen ist eine selur deutliche Trennung zwischen dem eigentlichen Pectoralis major und einer äussern, -chmalen Muskelpartie desselben, welche gar nicht ans Brutbein gelangt, sondern an den Knorpeln der falsehen Rippen in die Aponeurose des äussern Bauchnuakels übergeht Diese Partic könnte fïglich für einen eigenen Muskel angesehen werden, denn indem dieselbe, mit ihrem hinteren Theile am iussern Rande des Pectoralis major liegend, als dessen wheserntor Theil ersoheint, tritt sie, sich dem Arme nähernd, mehr wach innen an die obere, "den Rippén zugekehrte Flache des Pectoralis major, und kommt dadurch neben den m. pectoralis minor zu llegen, neben welchem sie sich an das tuberculum niau feinsehaig: ansetzt, während die Sehne des m. pectoralis major an der spina tuberculi majoris 

ziemlich in der Mitte des Oberarms endet. Obgleich so die Endsehnen dieser beiden Theile an getrennten Punkten inseriren, stehen dieselben doch mittelbar miteinander in Verbindung, indem die End-s sehne des oben beschriebenen Bauchhautmuskels sich zwischen ihnen ausspannt; dieselbe setzt sich nämlich theils mit der kleinern Partie vorbunden an die spina tuberculi minoris, theils mit dem eigentlichen grossen. Brustmuskel verhunden an die spina tuberculi majoris, indem sie schrig über den sulcus intertubercularis weggeht.

2. m. pectoralis minor reicht am Brustbeine von der zweiten bis siebenten Rippe, und liegt mit seinem hintersten 'Ende auf' dem vordersten des $m$. rectus abdominis, nit dein er sich verbindet; er geht nicht an den processus coracoideus, sondern an das tuberculum minus. Bei Sphinx soll er nach Meckel wenigstens theilweise an dem Schulterhaken inseriren.

3. Ein eigenthümlicher, dünner Muskel, den ich blos bei Cercopithecus gefunden habe, entspringt von dem Knorpel der ersten Rippe, geht bald aponeurotisch werdend, uber den zweiten und dritten Rippenknorpel weg, und dann in den ihm entgegentretenden Rectus abdominis über.

4. m, subclavius ist verhältnissmüssig stark, und geht vom Sternalende der ersten Rippe zu der ganzen hintern Fläche des Schlüsselbeins, 

- 5. m. serratu anticus major ist durch seine Stirke-aungezeichnet, verbinlet sich nach vorn mit dem Levator scapulae, entspringt aber übrigens wio beim Menschen von den neun vorderen Rippen.

VII. Muskeln am Oberarm und an der Schulter.

I. m. deltoideus gleicht den menschlichen.

2. m. uprasinatus ist auf Kosten des $m$. infra\& inatus verhültnissmässig stark.

3. mm. subsapularis, teres major und teres minor bieten nichts Benterkenswerthes dar. A. m. coracobrachialis besteht aus zwei von cinauder abstehenden Köpfen: der dem menschlicheu whnliche geht erst sput von dem kurzen Kopfe dea m. biceps ab, und setzt sich ziemlich in der Mitto des Oberarms fest; der zweite, weit kürzere Kopf nimmt schon vom processus coracoideus aus seinen gesonderten Lauf, und geht in gerader Richtung wach vorn, um sich an die vordere Fläche des Obarnom dicht unter dem Kopfe desselben anzusetsen. Zwischen beiden Köpfen heftet sich die Sehne des Teres major und des Latissimus dorsi an. Bei Capucina hat Meckel den obern Kopf nicht gefunden.

5. m. Liceps brachii soll sich nach Meckel in seinen beiden Köpfen früher vereinigen als beim Menschen, was ich aber nicht bestätigen kann. 



\section{$-26$}

6. 6. brachialis internus reicht höher hinauf als beim Menschen, und liegt mehr an der üussern als innern Eliche des Oberarms.

7. mm. anconei sind sehr stark, namentlich ist der lange Kopf, welcher fast von der ganzen Länge des üussern Randes des Schulterblatts entspringt, durch seine Breite ausgezeichnet; sie geben deshalb dera ganzen Oberarmo ein seitlich zusammengedrücktes Aussehn.

VIII. Muskeln am Vorderarme.

Bei dem Affen miissen die Muskeln am Vorderarme im Allgemeinen ein ganz andres Jagenverhiltniss zu dem übrigen Körper zeigen als beim Menschen, da bei ihm der Radius nicht sowohl neben, als vor der Ulna liegt, so nämlich, dass bei der Beugung des Ellenbogengelenks nicht wie bei dein Ménschen beide Knoclien des Vorderarms nebst der gauzen Volarfliche der Hand gleichmässig, son dern vielmehr der Radius und 'lor Radialrand der Hand vorzug weise dem oberarme genahert werden; hiernach ist es zu erklären, wenn in der folgenden Beschreibung der m. supinator longus nicht der äusserste, sondern der vorderste, der $m$. flexar carpí úlnáris nicht der innerste, sondern der hinterste Muskel genannt wird u. s. w.

1. n. flexor corpi ulnaris ist der hinterste Muskel des Vorlerarms, und von besonderer Stärke; er entsiringt vom condylus internus des Oberarms; 

ferner vou dem Olecranon und der innern Fläche Ner Ulne, und geht an das os pisiforme.

2. m. palmaris longus entspringt von der innern Flache des condylus internus; an der Hand findet sieh much ein schwacher m. palmaris brevis. 3. n. flexor carpi ravialis liegt vor und nach aunsen vom vorgenannten Muskel, und ontupringt wio dex folgende von der vordern Flïche des condylor internus, ist dann aber ijis fast zur Mitte des Vorderarns mit den mehr in Ner Tiefe liêgenden mm. pronator teres und flexor communis sublimis eng verbunden.

4. m. pronator teres geht bis iiber die Hälfte des Radius herab, und setzt sich sehnig an dessen vordorn Rand,

6. m floxordigitorumommis sublinfe ist bis zun Ende des ersten Drittheils des VorAerarm unzertrennlich mit dem profundus verwachsen; seine Sohnea zeigon die meinschlicho Bitdung.

6. m. flexor digitorn communis"profundus ist ungemein stark, und nimmt seineh Urprong ron dor ganzen innern Fläche des Vorderarms. Br tersalt in zwei Theile, welche nur durch cinen dünnen,, der Lünge 'nach verlaufenden' Sehnenstreifen verbunden sind. Der hintere dieser Theile entspringt längs der ganzén vordern und innern Flächo der Ulna, und geht mit seinen Sehnen zu dem fünften und vierten Finger; der vordere dagegen, dessen Sehnen für den dritten, zweiten und 



\section{$-28-$}

ersten Finger bestimmt sind, entspringt vom ligamentum interossoum und der ganzen innern Flache des Radius, und hat ausserilem einen starken Bauch, welcher, unzertrennlich mit dem Flexor sublimis verbunden yom condylus internuk entstehts:sa.

ine 7. m. flexor pollicis longus fehlt als eigener Muskel, und ist, wie eben benchrieben worden, uur ciu Iheil des tiefen gemeinschaftlichen Fingerbeugers. Nach Meckel soll bei Ateles auch nicht einmal eine Selnne vom letztgenannten Muskel zum Daumen gohen.

8. m. pronator quadratus ist verhaltnissmiassig breiter als bein Menschen.

9. m. supinator longus ist der vorderste Muskel des Vorderarms, dabei sehr tark, und bis ans Ende fleischig. Er reicht mit seinem Ursprunge sehr hoch über den condylus hinauf, und exscheint beim Affen als eigentlicher Beuger des Vorderarms; dabei scheint er durch verhältnissmäissig zu kurze Muskelfasern die völlige Streckung des Armes unmögtich zu machien.

7milosm. extensor carpi radialis longus und breyis liegen nach hinten zu neben dem vorigen Muskel, sind mit ihren Bäuchen fast ganz zu einem Muskel verschmolzen, haben mer mit ihren Schnen denselben Verlauf wie beim Menschen.

11. m. extensor digitorum communis geht wic bei dem Menschen zu den vier Fingern; bei Cercopithecus gicbt jerle seiner Sehnen Zweige 



\section{$-\quad 29$}

zu je rwei Fingern. Dicht neben ihm nach hinten su, ebenfalls vom conilylus extcrnus entspringend liegt:

$12 \mathrm{~m}$. extensor digiti quinti, welcher sich in swoi Sehnen spaltet, die zum vierten und fiinften Finger gehen, um sich dasellist ain ersten Gliele mit den Sehnen des vorgenannten Muskels zu vereinigen; bei Cercopithecus giebt die Sehne für den vierten Finger auch nooh einen Verbindungszweig an den dritten.

13. Vom gomoinschaftlichen Fingerstrecker hedeckt findet sich ein nur sohwacher Múskel, welcher, von dem ganzen, dem Radius zugekelirten Kande der Ulna und dem ligamentun interosscum entspringend, sich in der Nithe des Querlianiles der Hand in wei Theilo spaltet, von denen der eine ale m. extensor indicis, der andere als m. extonsor pollicis longus anzusehen ist; ersterer spaltet sich wieder in zwei Sohnen und setzt sich am ersten Gliedo des weiten und dritten Fingers an die Sehnen des gemeinschaftlichen Fingerstreckers nach aucien su an; letxterer geht nur an den Dauthen. Bei Patious oll nach Meckel der Extensor indicis vom Radius entspringen.

14. m. extensor pollicis brevis fehlt.

15. $n$. extensor carpi ulnaris entspringt am weitesten nach innen und hinten vom condylus externus, und geht nit seiner Sehne an den Mittelhandknochen des kléinen Fingers, aber méhr an die. 

Volar - als Dorsal -Fläche desselben, so dans er für sich nllein wirkend die Hand eher beugen als strecken, hauptsächlich aber nach hinten ziehen muss. 16. m. abductor pollicis longus ist sehr stark, sonst aber in seinem Ursprunge dem menschlichen gleich. Er gelangt mit seiner Sehne in eine tiefe Rinne am untern. Ende des Radius, und geht nun ganz nach der Volarfläche an den Mittelhandknochen des Daumens, setzt sich aber zugleich auch an das ligamentum volare proprium und an iden überzähligen Handwurzelknochen an, so lass er nicht den Daumen allein bewegt, sondern die ganze Hand etwas beugt und nach der Radialseite zieht; Meckel glaubt, dass der fehlende Extensor pollicis brevis mit ihm verschmolzen sei lichen.

17. m. supinat or brevis gleicht dem menschIX. Muskeln an der Hand.

1. m. abductor pollicis brevis entspringt mit zwei Portionen vom ligamentum volare proprium und sotzt sich an den Radialrand des ersten Daumengliedes, aber mehr nach der Volarfliche zu, an, so dass er bei der Abduction zugleich den Daumen. auch etwas beugen niuss.

2. m. opponens pollicis ist kleinẹ als beim Menschen; er entspringt vom ligamentum carpi volare proprium und dem tiberzlhligen Handwurzelknochen, und wetzt sich lings der ganzen Ausdely- 



\section{$-31$}

aung des Mittelhandknochens des Daumens, und zwar an der Volarfluche desselben, fest.

3. m mi: flexor pollicis brevis und adductorpollicis sind mitihren Băuchen ganz eng verbunderi, und entspringen von der ganzen Volarfläche desdritten Mittelhandknochens, ferner vom os multangulum maju und capitntum; der erstere trennt sich in swei Partieen, die sioh kurzsehnig an heiden Seiten dea eraten Daumengliedes ansetzen, indem sie die den langen Beuger vertretende Sehne swischen nich fasaen; dor Adductor setzt sich daneben an die Ulnarseite dexaelbon Knochens fest.

4. m. abductor digiti minimi ist grösser als bein Menschen, weil das Erbsenbein beim $\Lambda$ ffen mehr nach dem Vorderarme hin gerïckt ist.

5. m. floxor brovisdigiti minimi fehlt.

6. mopponons oder besser adductor digiti minimi zoigt nichts von der menschlichen Bildung Abweichenden; eben wo die $\mathrm{mm}$. I u mbricalox.

7. mm. interossei interni gleichen den menschlichen, ausser dass sie an der Hohlhand untex einander verwachsen sind, und der für den Zeigefinger bestimmte nur kurz ist; die externi ver-: halten sich wie die des Menschen.

X. Muakeln des Baches.

1. m. obliquus abdominis externus ist verhältnissmänsig eben so breit als beim Menschen, 

hat aber nicht so lange Muskelfasern. Er entspringt vorn von den acht hintern Rippen, ferner weiter nach hinten yon der den Bauchmuskeln und den breiten Rückenmuskeln gemeinschaftlichen fascia lumbodorsalis, und bekommt endlich im Vorbeigehen noch einigo wenige Fasern von dex spina anterior superior ossis ilii. Yon diesem Ursprunge aus geht ex vie boim Menschea zur linen alba und zur synphysis ossium pubis schrig nach unten und hinten hinab. Bei dem Menschen bildet bekanntlich der untere, zwischen der spina anterior nuperior ossis ilii und der Schaambeinverbinilung ausgespannte Rand des ikusseren Bauchmuskels, oder das sogenannte Poupartsche Band, den untern Schenkel des Leistenringes und zugleich die Decke des Schenkelringes; anders verhălt es sich aber bei dem Affen. Bei der sehr in die Länge gezogenen Form des Darmbeins desselben würde nämlich zwischen dem von der spina anterior superior ilii zur symphysis pubis: gehenden hintern Rande des äussern schieten Bauchmuskels, dem untern Rando des Darmleins, und dem horizontalen Aste des Schambeins ein sehr grosser dreieckiger Raum offen bleiben, wenn nicht hinter Jenem Rande der innere schiefe Bauchmuskel noch cine bedeutende Strecke wait unbedeckt hervorragte jenen Raum bis auf einen kleinen Theil verschliessend. Man muss demnach den hintern Rand, des : iusgern Bauchmuskcls beim Affen, aumal er keine bandartige Verdichtung 

xeigt; nicht mit dem Namen des Poupartschen Banden belegen, und dieses dem innern schiefen Bauchmuskel xuschreiben, oder von demselben erklïren, dase en nicht den Sehenkelbogen, sondern nur den hiatern oder Mussern Schenkel, des Leistenringes bilde. Auch zeigt der Leistenring beim Affen noch oinige Abweichungen; sein vorderer oder innerer Sehenkel geht nalmich an die Syraphysis pubis, durehkreust wioh nber nicht mit dem der andern Seito; der hintere oder äussere Schenkel befestigt aick an den horisontalen Ast des Schanmbeins bis sa dessen Hocker hin; von letzierem gehen noch foine. Sehnenfasern nach dem Schenkelringe hin, wolohe ein unvollkommne Gimbernatsches Banil darstellen; die von diesen beiden Schenkeln gebildete Oeffnung endlich ateht weit offen, und likst den innera dehiefen Bauchmuskel frei sehen.

2. m. obliquus abilominis internus entapringt von dex den breiten Bauch und RüokonMuskeln gemeinschaftlichen fascia lumbodorsalis, haupestachlich aber von dem ganzen untern Rande dez Darmbeinx, und zeigt im Allgemeinen hinsichts der Richtung seiaer Fasern dieselbe Einrichtung wie bei dem Menschen. Bemerkenswerth ist aber sein hinterater Theil. Indem dor Muskel nämlich mit seinem hintern, der Pfanne sehr naheliegenden Ende den untern Rand des Darmbeins verlässt, geht er mit oinem freien Randle, welcher einen Bogen mit der. Concavitat nach hinten bildet, nach innen zu, und 


\section{-}


setzt sich aponeurotisch an den innern Theil ler Schaambeinleiste: an. Dieser bogenförmige freie Rand bildet den Schenkelbogen, zwischen welchem und dem äussorsten Theile des Schaambeins abér nicht nur der m. psoas und iliacus internus, die a. und $v$. cruralis und dering oruralis, sóndern. auch der Snamenstrang mit dom Cromnster hindurchgeht, welcher danin ergt von dem durch die Schenkel des aussern schiefen Bauchmuskels gebildeten Leistenringe aufgenommen wird." So vertritt denn hier der Schenkelring auch zugleich die Stelle des inwendigen Theils des I.eistencanals. Der m. cremater ist beim Affen doppelt inden zu seinem wesentlichen Theile; welcher sich als eine Fortsetzung des innern schiefen und des transpersellen Bauchmuskels zu erkennen giebt, noch ein dünner Muskel hinzutritt, welcher von dem äussersten Ende des horicontalen Astes des Schaambeins entspringt; der ganze Muskel erscheint übrigens am Hoden viel stärker als beim Menschen.

3. m. transversu abdominis fot unter den Bauchmuskeln der breiteste, und hat mit dem des Menschen gleichen Ursprung; sein hinterster muskulöser Theil ist mit dem innern schiefen Bauchmuskél eng verbunden.

4. m. rectus abdominis reicht bei Inuus und Cynocephalus vom Schambeine bis zur fünften Rippe, bei Cercopithecus aber bis zur vierten, oder wenn wir jenen kleinen, unter VI. No. 3. beschrie- 

benen Muskel als einen durch Zwischensehnen getrennten Bauch ansehen wollen, selbst bis zur ersten Rippe. Bei den ersten beiden Affenarten fand ich viet bis funf, nicht gane durchgehende tendinase Inacriptionen, bei der letzten aber konnte ich ticht dergleichen wahrnehmen.

6) 5. m. pyramidalis ist nicht zu finden, und scheint an weiner Stella dia Scheide des Rectus al)dominis dureh eigenthtimliche schriggerlaufende Schnenfasern eine Verstïrkung zu erhalten; dio ganze den Rectus abdominis einschlicssende aponeurotische Scheide ist fubrigens viel leichter als bei dem Menwehen in ihre einzelnen, den verschiedenen breiten Bauchmuskeln angehörigen Blutter: au spalten. Bei Ateles soll nach Meckel ein Pyranidenmuskel vorhanden sein.

\section{Muskeln am Sohwanze.}

1. m. levator caudae externus fült dic Grube zwischen den Querfortsătzen und den schiefen Fortsätzen aus, entspringt fleischig von den Wehlefen Fortultzen der hintern Lendenwirlsel, ferner der Heiligenbeinwirbel und endlich der vordern Schwanxwirbel, und geht mit dünnen, zun Theil sehr langen Sehnen an die Basis der hinteren Schwanzwirbel. Bei Inuius reicht er nit scinem Ursprungo bis zum dritten Lendenwirbel, woselbst nein Bauch zwischen dem m. multifidus spinae und dem m. quadratus Inmborum liegt, und geht mit ei- 

ner einzigen Sehne an den dritten Schwanzwirbel; bei Cynocephalus und Cercopithecus entspringt or vom vierten Lendenwirbel bis etwa zum fünften odler sechsten Schwanzwirbel, und setzt sich mit vielen Sehnen an alle folgenden Schwanzwirbel an.

2. m. levator caudae internus seheint mir dem m. multifidus spinae zu entsprechen, fullt den Raum zwischen den schiefen und den Dorn-Fortsätsen aus, und geht mit seinen einzelnen Bündelchen theils von ersteren zu letzteren, theils von einen Dornfortsatze zum andern.

3. m. ischiococeygeus geht von der innern Flache des Sitzbeins unterhalb der Pfanne zu den Querfortsătzen der ersten Sehwanzwirbel, nămlich bei Inuus su allen drei, bei Cynocephalus und Cercopithecus aber zu den vier bis fünf vordersten Schwanzwirbeln.

4. mm. intertransversarii caudae gehen von einem Querfortsatze der Schwanzwirbel zum andern, sind aber bei Inuus nicht aufatinden.

6. mm. infracoccygoi (Meckel) liegen in der Mittellinie unter dem Schwanze, gehen von einem Wirbelkörper zum andern, und sind nur da deutlich, wo dieser cine spina hat.

6. m. iliococcygeus kommt von der innern Seite des Darmbeins, da wo sich dasselbe mit den Sitzbeine verbindet, bildet ein längliches Fleischbündel, und setzt sich an den Körper der drei vor- 

dern Schwanzwirbel; ist bei Inuus ganz so wie bei den beiden andern Affenarten gebildet.

7. m. pubococcygeus kommt dünn, aber breit, vom horizontalen Aste des Sehaambeins, und setzt sich schmäler werdend mit dem der andern Seite gemeinschaftlich an die vier bis fünf ersten, bei Inuus an alle drei Schwanzwirbelkörper an.

8. $\mathrm{m}$, sacrococeygeus inferior (Cuvier) geht von der innern Flache des Heiligenbeins nach hinten, liegt zwischen den Querfortsătzen und den untorn Dornen der ersten Schwanzwirbel und setzt wich mit seinen Sohnen an die untre Fluche so vieler Schwanzwirbel an, als Sehnen von dem $m$, levitor caudae externus erhalten haben.

XII. Muskeln des Afters und der Gechloohtstheile.

Dio Muskeln der männlichen Geschlechtstheile des Affen zeigen wenig Aohnlichkeit mit denen des Menschen, was grossen Theils durch den abweichenden Verlauf der Harnröhre bedingt wird.

15. Von dem absteigenden Aste des Schanmboins, noben dan arcui pubies entspringt ein dünner, bei Sylvanus und Cynocephalus etwa anderthalb Zoll langer Muskel, welcher schräg nach innen herabsteigend sich mit dem der andern Seite vereinigt an die Mittellinie des Rüekens der Ruthe ansetzt, und dievelbe nach dem Bauche zu surückziehen muss; nach aussen von demselben findet sich auf jeder Seite ein 
ligamentum suspensorium, welches sioh früher als der Muskel, und mehr, zur Scite an die Ruthe befestigt.

2. Dicht neben dem vorigen. Muskel melsr nach aussen und hinten liegt ein kurzer aber sehr dicker Muskel, welcher von der Hussern, Flüche des aufsteigenden Astes und dem untersten Theile des Sitzbeines entspringend die Zellenkörper der Ruthe seitlich, sowohl oben als unten umfasst, und an ihnen endet. Zwischen den beidersoitigen Muskeln verlaufen oben die Blutgeffusse der Ruthe, und bleibt unten eine Rinne, in welcher sich die mit keinem corpus cavernosum ausgerüntete Harnröhre hinzieht. Dieser Muskel würde wohl dem menschlichen Ischiocavernosus entsprechen.

3. Zwischen den beiden Sitzbeinhồckern ist an der nach hinten gekehrten Fläche eine aus starken Querfasern bestehende sehnige Haut von dem innern Rande des einen zu dem des andern ausgespannt. Entfernt man diese Sehnenhaut, so findet man einen sehr starken, unparigen Mackel, welcher den Raum zwischen den beiden Sitzbeinhöckern ausfullend nirgends vom Kuochen entspringt, und dessen beiderseitige Hälften wohl durch sehnige Streifen angedeutet werden, nicht aber ohne Gewalt von cinander getrennt werden können. Die beiderseitigen Hälften dieses Muskels nehmen ihren Anfang mit kurzen Sehnenfasern, von des untern und vordern, der Schaambeinvereinigung zugekehr- 

ten Fläche des bulbus urethrae, gehen nun aufwirts nit parallelen Fasern um denselben herum, unil endigen sich, in einanter übergehend, in der Mittellinie zwischen den beiden Sitzbzinhöckern, indem sie zugleich längs der Mitte der obengenannten Sch-: nenhaut befestigt sind. Es würde dieşer Muskel wohl ein tark; ausgebildeter. Bulbocaverposus zu nepnen sein.

4. Von dem vorgenannten Nuskel geht ein langer aber dünner, durchaus nnpiariger Aftermuskel aus; derselbe nimmt nämlich an der Seite des vordersten Theiles des Buffoctuernosus seinen Anfang, geht nach dem Heiligenbeine zu schriig nach vorne in die Höhe, schlägt sich un die obere Flliche des hintern Endes des Mastdarms bogenförmig herum, und geht endlich wieder absteigend $z u$ derselben Stelle der andern Halfte des Muskels zurïck. Er muss den After herabziehen, und indem er ihn gegen den Bulbocavernosus andrlickt zugleich verschliessen.

5. Von der Mittellinie der obern Flitche des Bulbocavernosus gohen aus dessen vorlerstem Ende Muskelfasern gerade nach vorn zum Sphincter ani externus, von welchen ich dahin gestellt sein lasse, ob sie als ein eigener Muskel, oder nur als cine Portion des Bulbocavernosus zu betrachten sind.

250. Die Schliesser des Af terszeigen nichts Bemerkenswerthes, ausser daş der äusserc vollkom- 

men ringförmig ist, und nicht 'wie bei dem Menschen an dem Steissbeine inserirt.

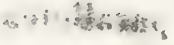

- Ein m. levator ani entspringt auf jeder Seite schmal von der innern Fliche des hintern Heiligenbeinwirbels, und geht breiterwerdend an die untere Fläche des Afters.

8. Einen m. trans versus perinaei habe ich nicht finden können, und wird derselbe wohl durch jene zwischen den beilen Sitzbeinhöckern ausgespannte Sehnenhaut vertreten.

9. Von den Muskeln der weiblichen Geschlechtstheile habe ich nichts zu erwähnen.

XIII. Muskeln, welche innerhalb der Bauch höhle liegon.

1. m. diaphragma zeigt sich dem menschlichen ziemlich gleich gebildet. Das Centrum tendineum ist herzförmig mit einer mittleren Spitze nach dem Brustbeine, mit zwei divergirenden Schenkẹ!n nach dem Rücken hin auslaufend. An der pars lumbalis lassen sich nur zwei Schenkel upterscheiden; der innere geht bis zur Mitte des Korpers des zweiten Lendenwirbels, und ist auf der linken Seite nur wenig kürzer als auf der rechten; der äussere Schenkel ist durch einen Bogen, welcher sich über den vordersten Theil des m. psoas heruberwölbt, von dem innern getrennt, inserirt an den Querfortsätzen der zwei bis drei ersten Lendenwirbel, und geht aach aussen in die pars costalis über. 

2. m. quadroturs lumborum, welcher sehr in dio Lüne gezogen; dabei aber schwächlich erscheint, ontspringt nicht von dem vordern sondern von dem oberen Rande des Darmbeins, und reicht bis zum elften Brustwirbel:s

30t m. psoas minor ist verhältnissmulssig sehr stark, entspringt mit vier Zacken von dem letzten Brustwirbel bis zum dritten I.endenwirbel, hängt mit dem Quadratus Ińborum und Psoas major durch fleischige 'Zacken zusammen, und billet eine breite Sehne, mit welcher er sich an die linea arcuata des Darmbeins festretzt.

4. m. psoas maj or entspringt mit fünf Zacken von den fünf vordersten Lendenwirbeln, und geht mit dem lliacus internu eine unauflösliche Verbin. dung ein.

6. m. iliacus internus ist, der Form des Darmbeins gematss, in die Lünge gezogen, und geht mit dem Proas major zum trochanter minor.

XIV. Muskeln an der ăussern Fläche qes Beckens, und am Oberschenkel.

1. m. glutaous maximu ist vicl dünner als beim Menschen. Er entspringt vom obern, vordern und vom grössten Theile des untern Randes des Darmbeins mit einer Aponeurose, welche den $m$. glutaeus medius bedeckt, ferner nuskulös nur von den drei bis vier ersten Schwanzwirbeln, und von der Mitte des untern Randes des Darmbeins. Die 

von der letztgenannten Stelle komnende Muskelpartie, welche aber von dem :ibrigen Muskel micht zu trennen ist, stellt den m. tensor fasciae latae dar, welcher sonst ganz fehlen würde. Bei Ateles, Jacchus und Capucina soll nach Meckel der 'Tensor fasciae latae vom Glutaeus getrennt bestehen. Der ganze Muskel setzt wich nun mit seinem kleinsten, hintersten Theile untor dem trochanter major fest; mit seinem grösseren, vorderen Theile geht er in eine Aponeurose über, welche als fascia laca sich bis zum Unterschenkel heraberstréckt.

2. m. glutaeus medius ist der stärkste Gesăssmuskel, entspringt munkulös von deni ganzen vordern und obern Rande des Darmbcins, und geht fast ganz gerade zum trochanter major hini sys whe

3. m. glutacus minimus kommt von der Mitte der äussern Fläche des Darmbeins, und von dessen hinterem Ranile bis an die spina ischiadica, und geht an den vordern Theil des trochanter major.

4. m. py rif ormis fehlt nicht, wie Meckel be: hauptet, bei Inuus, sondern ist nur vom Glataeus minimus verdeckt, mit lessen Sehne eng verbunden, und an sich sehr sehwach. Er koumt an der incisura ischiadica zum Vorschein, und geht fast senkrecht abwirts zum grossen Trochanter; er belleckt len n. ischiadieus bei dessen Austritte.

ho 5. mm. obturatoriusexternus undintern us zcigen uichts Bemerkenswerthes. 



\section{$-43-$}

6. mm. gesuini sind schwach, sonst aber dcn menschlichen gleich; der superior fehlt nicht bci Inuus, wis Meckel angiebt.

7. m. quadratus femoris zeigt sich nicht so quadratisch und querlaufend wie bei dem Menschen, soudern ist länglich, und geht in schiefer Riçhtung unter den Trochanter hinal, 'so dass er den Schenkel nicht sowohl nach aussen rollt, als vielmehr aach hiuten aufhebt:

8. m. gracilis ist bei Affen sehr breit, indem ex. lings der ganzen S'chaumbeinvereinigung entapringt, und setzt sieh unter dem folgenden Muskel an die Tibia bis fast zu deren Mittc herals an, wonelbst er auch theilweise in die fascia suralis übergeht.

9. m. sartorius endigt sehr tief unterhalb des Knies, und scheint; eben so wie der vorgenannte Muakel und dic unter No, 15 und 16 angeführten, dex vollkommnen Streckung des Unterschenkels im Wege zu stehn.

10. m. pectinaeus setzt sich dicht unter den m. iliacus internus an.

11. m. adductor femoris ist nicht drei-sondern mehrköptige Ich unterscheide finf Köpfe: der hinterste ist schmal und lang, entspringt dicht über dem Sitzbeinhöcker vom ramus adscendens ischii, und setzt sich oberhalb des condylus internus an den Oberschenkel; der zweite, etwas weiter nach vorn liegende Kouf ist der breiteste, an scinem Ursprunge ziemlich genau, mit den vorigen verbunden, und in- 
serirt an der ganzen untern Hälfte des Oberschenkels, und zwar an der Mitte der hintern Fliche desselben, während der vorige nehr an der inner Seite bleilbt; der dritte Kopf ist breit und dünn, entspringt vom Gracilis bedeckt von der ganzen Symphysis pubis, und setzt sich aponeurotisch über dem vorigen; etwa bis zur Mitte des Oberschenkels an; der viette, schmale Kopf entspringt vom vordern Ende der Schaambeinvereinigung, und hat für seine Aponeurose denselben Ansatz als der vorige, von dem er aber deutlich zu unterscheiden ist; endlich der fïfte Kopf ist nur sehr kurz, entspringt von dem vorigen und dem 'm. pectinaeas bedeckt vom vordern Winkel des Schaambeins, und setzt sich dicht unter letzterem an den Oberschenkel. Meckel zählt ausser den Pectinacus noch sechs Adductoren.

12. m. rectus femoris entspringt nur mit einer Sehne vom untern Rande des Darmbeins etwas vor der Pfanne, und ist von dem m. vastus internus bis zum Knie leicht zu trennen, dagegen mit dem externus von der Mitte des Oberachenkels an fest verrbunden.

13. m. vastus externus ist sehr stark, und entspringt von den trochanter major und dicht unter demselben, bekommt aber weiter unten keine Fasern vom Schenkelbeine.

14. m. vastus internus reicht oben bis zum Hals des Oberschenkels, und ist nit dem, dem menschlichen gleich gebildeten m. cruralis eng 



\section{$-45-$}

verwachsen, so dass er mit diesem eben so einen tiefliegenden zweiköpfigen Muskel larstellt, wie der m. vastus externus mit dem $\mathrm{m}$, rectus femoris einen oberflächlichen.

15. n. biceps femoris ist bei den Affen nicht zweiköpfig, indem er nur von dem Sitzbeinhöcker entspringt, und als ein breiter, starker Muskel sich an der ganzen obern Halfte des Unterschenkels hauptianchlich in fie paseia suralis endigt.

16. m, semitendinosus setzt sich mit der Sehne dog $m$. gracilis an dem zweiten Drittheile der Tibia fest, ist aber nicht so langsehnig als bei dem Menschen.

17. m. semimembranosus reicht nicht so weit herab als der vorgenannte Muskel.

\section{MuskeIn om Unterschenkel.}

1. m. tiblalis anticus ist tief herab fleischig und inserirt an dex untern Fläche des ersten Keilbeing. Zwischen dienem und dem folgenden Muskel findet sich bei Inuus und Cynocephalus ein besonderer, ziemlich starker Muskel, welcher vom Schienund Wadeabeine entapringend mit einer langen Sehne an die innere Seite der Basis der grossen Zehe geht; bei Cercopithecus ist dieser Muskel nicht so deutlich gesondert, sondern orscheint als ein zweiter Kopf des Tibialis anticus; jedenfalls aber ist derselbe als ein m. abductor longus hallucis zu betrachten. 

2. m. extens or longus halluciszeigt nichts Abweichendes.

3. m. extensor digitorum communis lon$\mathrm{g}$ us ist verhältnissmaissig schwach, und seine Spaltung in vier Selinen geschieht erst auf dem Fussrücken.

4. n. peronaeus brevis entspringt von der Mitte der Fibula abwärts von deren vordern, besonders aber äusseru Fläche, ist bis zur Rinne hinter dem malleolus externus fleischig, und setzt sich mit starker Sehne an die aussere Fläche der Basis des fünften Mittelfussknochens.

5. m. peronatus tertius entupringt dicht uber dem vorigen Musket, ist aber bcim Affen ein m. abductor digiti quinti longus, denn er geht, an seinen Bauche von dem vorigen und dem folgenden Muskel eingeschlossen, 'neben diesen mit seiner diunnen Sehne durch dieselbe Scheide, um endlich an der äussern Seite des ersten Gliedes der fünften Zehe sich mit der für diesebestimmte Sehne des $\mathrm{m}$. extensor communis digitorum longus zu verbinden. Mecket nennt diesen Muskel einen eigenen Strecker der fünten Zehe, womit ich aber deshalb nicht einverstanden bin, weil derwelbe nioht wie die Extensoren der Zehen und wie der Peronaeus tertivis beim Menschen von der Dorsalseite des Fusses herkommt, sondern mehr nach der Volarseite zu und ganz nach aussen liegt. 
6. m. peronaeus longus zeigt niehts Bemerkenswerthes.

7. m. gastrocnemius ersheint mehr in lie Lunge gezogen, sonst aber nicht schwächer als beim Menschen, denn er ist bis zum untersten Viertel des Schenkels herab fleischig, und geht dann in die Achillessehne uiber, welche sich mehr nach innen als nach aussen an den Tuber calcanei ansetzt. Sowoht am tussern als am innern condylus des Oberschenkels finden sich ani Ansatze dieses Muskels Sesambeinchen.

8. m. plantaris hat mit dem äussern Kopfe des Gastrocnenius gemeinschaftlichen Ursprung, und liegt vor diesem etwas nach innen. Er ist bedeutend grösser als beim Menschen, bis uiber die Mitte des Schenkels herab muskulös, und seine Sehne tritt unten neben der des Gastrocnemius niteh innen hervor, geht unter dem Calcaneus fort, und breitet sieh dann als fascin prantâns aus. Diese letztere theilt sich in drei Theile: der erste endet an der Grosszehenseite der Fusswurzel, und dient der kleinern Portion des $\mathrm{m}$. flexor digitorum communis brevis und dem m. abductor hallucis brevis zum Ansatz; der zweite geht zur zweiten und dritten Zehe,

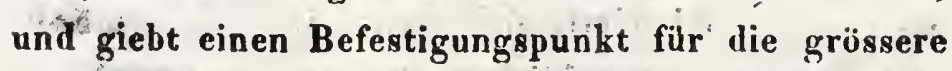
Portion des $\mathrm{m}$. flexor digitorum communis brevis ab; der dritte endlich verliert sich an der vierten und finften Zehe, nachdem er sich schon an Mittelfussknochen der fünften Zehe befestigt hat. 


\section{$-48-$}

9. m. poplitaeus ist viel stärker als bei dem Menschen; er geht von der äussern Flächo des condylus externus zar innern Fläche der Tibia, woselbst er breit inserirt.

10. m. colcus entspringt von der hintern Flache des äussern Condylus der Tibia und ron dem Köpfchen der Fibula, und ist fast bin zum Calcaneus herab vom Gastroenemius zu trennen.

11. m. flexor digitorum communis longus hat an seinem Ursprunge nichts Abweichendes, und beaitzt auch eine caro quadrata, welche von der äussern Fläche des Calcaneus entspringt. Er spaltet sich erst am Fusse in die fuir vier Zehen bestimmten Sehnen, und vọ diesen sind die beiden innern so innig mit der des $\mathrm{m}$. flexor hallueis verbunden, dass bei seiner Wirkung die grosse Zehe mitbewegt werden muss.

12. m. floxorhallucis longus ist sehr stark, zumal an seiner untern, hauptsächlich vom ligamentum interosseum entspringenden Hulfte. Er ist nicht nur für die grosse, sondern auch für mohrere andero Zehen bestimmt, denn er läuft in zwei Sehnen aus, von denen die innere allein zur grossen Zehe geht, die andere dagegen sich wieder spaltend an die sweite und vierte Zehe geht, um mit den Sehnen des gemeinschaftlichen Beugers zu verschmelzen. Die für die grosse Zehe bestimmte Sehne deswelben geht $x$ wischen den dem langen gemeinschaftlichen Beuger zugehörigen Sehnen für die 



\section{$-\quad+0$}

zweite und dritte Zehe hindurch, und verbindet sich dabei nit beiden so $^{-}$genau, dass man hinter der Durchgangsstelle nur mit Mühe unterscheiden kann, welche Sobne den Flexor hallucis und welche dem Gloxor communis angehört. Nach Meckel soll die zuerst erwähnte Sehne dieses Muskels an alle vier äussern Zehen gehen, und nach Cuvier an die dritte und vierte; möglicher Weise kommen hierin Varietaten vor, die aber die Hauptsache nicht ändern.

\section{SVI, Muskeln an Fuse.}

1. n. flexor digitorum communis brevis ist nirgends an Knochen angeheftet, sondern entspringt theils von der Sehnenhaut der Fusssohle, theils von der noch ungetheilten Selnne des langen gemeinschaftlichon Beugers, und, geht mit drei Sehnen zu den drei wussern Zehen. Zu ihm tritt noch eine kleinere Portion, welche nelen dem Abductor hallucis brevis liegt, von der untern Fläche des Ferscnhöckers, hauptsächlich aber von der fascia plantaris entspringt, und zur zweiten Zehe geht.

stishormeductiothallueis brevis kommt mit dem vorigen Muskel von dem Calcaneus und der fascir plantaris, bekommt aber noch einen äussern Kopf, welcher vom ersten und zweiten Keilbeine entspringt, und einen inneren, der ganz am innern Rande les Fusses liegend von der Seite des ersten Keill,eines entsteht: 

3. m. flexor hallucis brevis igleicht dem menschlichen:

asto moduct or hall uci is ist stärker als beini Menschen, und zerfillt in einen grbssern hinteren und einen kleineren vorderen odtorstueren Kopf: Beide Köpfe, und besonders dor queres entspringen weiter nach innen als vein Mensehen, nitmlich am zweiten Mittelfussknochen, und setzen sich nicht blos: andie Basis, sondern an das ganze erste Glied - der Zehe an.

5. m. abductor digiti minimi brevis kommt vom äussersten Ende des 'Tuber calcanei, bekomnic we beim Mensehen noch einen ziveiten Kopf voni Wurfelbeine, und geht mit einer langen Sehne ans erste Glied.

6. m. flexor digiti minimi brevis ist in seinem Anfange mit den zweiten Kopfe des vorigen Muskela verbinden.

7. in m. interossei interni haben dieselle Einrichtung wie die gleichnanigen an der menochlichen Hand. Sie entspringen von der Basis der Mitfelfuseknochen der zweiten", dritten und vierten Zehejund geken an dio der Mittelzehe zugewendete Seite der zweitengovierten und finften Zohe, dass al die mittlere Zehe keinen selehen Muskel bekommt. acises zot. 8. m. extensor digitorum communis breyis ist für die grosse und für lrei andre Zehen bestimnt, dagegen für die fünfte nicht. Die Seh- 

nen gehen an die tursscre Seite des ersten Zehengliefles, und verbinilen sioh: mit den Schnen des Extensor communis longus: bis - .

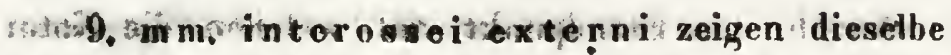
USinvohning wie die gleichnhmigen Muskeln an der monschlichen Hand, nur mit dem Unterschiede, ilass sie nicht von je zwei Mittelfussknochén, $9:$ sonJern von der seite eines Mittelfussknochens entspringen, tw welcher sie km ersten Zehengliede gchen; und dass ferner ein iblerzihliger sich auch on der ausserniseito der zweiten Zehe befindet.

Betrachtung der Muskeln des Affen, insofern sie einen Unterschied desselben von dem

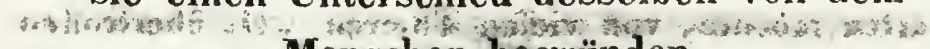
Menschen begründen.

Dio vorstehende Beschreibung yeigt uns in den beiweiten mejsten Mueholn des Afienkörperg eine grössere oder geringere $\mathrm{Ab}$ weichung von der menschlichen Bildung; alber so zahlreich auch diese $\mathrm{Ab}$ weichungen sein moggen; sie könnten bei der grossen Mannigfoltigheitudorum in Muskelsysteme auch hei ein und derselben Thierart, vorkommenden $\mathrm{Va-}$ rietaten, und bei der Abhängigkeit der äussern Form der Mudkeln von der der Knochen, nur von geringex Wichtigkeik: für uns sein, wenn wir nicht dic Funktionen dex Muskeln, die Art und Wẹise der durch wic hervorgebrachten Bewegung zu bestimmen, 



\section{- 52}

wenn wir uns nicht dadurch ein Bild vonsiden aktiven Verrichtungen und der Lebensweisedes Thieres zu verschoffen, und wenn wir nicht endioh hiernach den Standpunkt auf welehen die Natur dieses Thier gestellt hat, mithin slas Verhältniss desseltven zur Menscliheit: zu abourtheilen versuchen

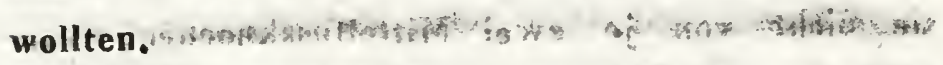
Demi Beobachter der lebendigen Natur kann es nicht entgehen, dass der Menseh weder durch die

- Organe des rein plastischen Lebens, noch auch durch die höheren Sinnesorgane sich wesentlich von dem Thiere unterscheidet, ja dass derselbe sogar in der Schärfo und Ausbildung der letateren, welche man doch bei ihm, als dem vollkommensten Geschöpfe, auch am vollkommensten entwickelt zu finden erwarten möchte, von vielen Thieren weit übertroffen wird. Nicht das Vermögen, Eindrücke von der Aussenwelt her in wich aufunehmen, sondern umgekehrt die Fihigkeit, seine innere, geistige Natur nach aussen hin werk thätig zu zeigen, unterseheidet körperlich den Menschen von dem Thiore; diese Fahigkeit duber gewähren ihm: sein bewegliches Antlitz, seine Sprache, sein aufrechter Gang und seine beiden Hände. Das freie, beweglishe Antlitz, diesen treuen Spiegel der Seele; die Sprache, als das Vermögen, Jurch die mannigfaltigsten articulirten Laùte die Regungen des innern Lebens ${ }^{7}$ kund zu thun; den aufrechten Gang, durch welchen nicht allein das Haupt von dem Erdboden erhoben, sondern auch 

die freiste Bewegung der Gliedmassen möglich gemacht wird; endlieh die Hände, diese bewundernswürdigen Werkzeuge, welche Werke der Kunst zu schaffen, und musikalische Instrumente zu beleben vermögen, hat der Mensch vor allen : Thieren voraus, und alle verdankt er, soweit sie nänlich überhaupt dem Körper angehören, fast lediglich der besonderen Einxiohtung seiner Muskeln. Indem nur die Muskeln Gegenstand dieser Abhandlung sein sollen, will ich es versuchen, nich lediglich auf eine vergleichende Betrachtung dieser beschränkend darzuthun, dass in allen den eben genannten Punkten der Affe den Menschen sehr fern stehe, und sich nicht von der Reihe der eigentlichen 'Thiere tosmache.

Das Antlitz des Mensohen ist mit einem sehr reichen Apparate yon Muskeln versehen, welche dem Gesichte bis in die kleinsten Theile die mannigfaltigsten Bewegungen mittheilen konnen. Zwwar laufen die meisten dieser Muskeln in convergirender Richtung nach dem Munde zin, so inseriren namentlich in der Oberlipue allein sieben Muskelparre, aber jedor einzelne hat eine besondre, von der der andern abweichende Bewegung, und ist deshalb auch weniger als dies an jedem andern Körpertheile ider Fall ist, mit den ihm benachbarten: Muskeln versechnolzen, vielmehr durch interstiticlle Fettmassen, die auch bei dem magersten Individuum nic ganz fehlen; in seiner Selbststindigkeit be- 



\section{$-54-$}

wahrt. : Da dieser Muskelapparat unter dex unmittelbaren Hersshaft gewisser Sinnesnerven steht, gielit er mit Blitzesschnelle jede Regung der Seele, and zwar auf eine besondre, und unterscheilbare Weise kund, es sei denn dass Ueberbildung die Gesichtsnerven gelehrt habe, dio Regungen der Seele zu verheimlichen, voder gar nicht vorhandene zu-simulirenio Ganz anders verhatt es sich mit den Thieren: sio vermögen nur in Allgemeinen die aufregenden und die deprinirenden Affeote, ind zwan witht wowohl durch das Gesicht, als durch die Muskulatur dles ganzen Körpers auszudrücken. Das : Gefühl dew Wohlbehingens, dew Muthes und der Freule drïckt sich hel ihnen furch rasehe, muntere, zwecklose Bewegungen ihres ganzen Körpers, das des Unbehagens, der Furcht und der Trauer dureh Ersohlaffung aller ihrer Muskeln, namentlich der erigirenden, und Aureh Depression:ähres ganzen Körpers aus, welche Zeichen bei den mit beweglichen Schwanze versehenen Thierer sioh an diesend verzugsweise deutlich bemerkbar mathen. Die Muskela des Gesichts nehmen an diesen algenreinen Körperbewegungen nur verhülthissmässig wenig bemerkbaren Antheil und können fir sick alleiv lier derrimeisten Thieren gar keinendimern Affect wathnehmbar maehen. Wollte man etwa dic Bewegungen der Ohrmuschel bei einigen Thieren als ein Analogon unsres Minenspiels ansehen, dais $B_{\text {. der }}$ aufmerksame Reiter durch das Ohrenspitzen seires 
, 
muthigen Pferdes vor setwanigen Unarten desselben gewarnt wird, so ist nicht za übersehen, dass diese Ohrbewegung nicht sowohl der Ausdruck eines Vorganges ins Innern, als vielmetr nur das Zeichen eines auf das Hörorgan treffénden Hussern Eindrucks ist, auf welchen allertings möglicher Weise ein innerer Affect folgen kann. - Betrachten wir nun AnsiGesioht des Aften, so. treffen wir nïchst den

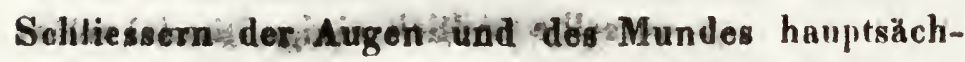
lich nur zwei starke Muskelparticen in, welche nur durich küntliche Trennung in einzelne, gewissen Gesichtsmuskelnides Mènwichen entsprechende Bilnz del zerlegt werden können, und welche theils von oben gerade abwhrts, theils von Kinne gerade aufwärts zun Oher- und Unterlippentheil des 'm. orbiculavis oris gehend, wlie Wirkung haben missen, die Lippen von cinander zitentfernen; und dadurch dí. Zhhwe zulentblössen. Nur ein einziger Muskel, der unter Il. No, 8. angefubrto; thit sich von jenen beiden Muskelpartieen mehr gesonilert, und muss seine eigenthümliche Verrichtung haben, welche wie ich glaube darin besteht, die Oberlippe nach vorn whischieben; undiduduroh das Maul spity zu machen. So sehen wir denn die Gesichtsınuskeln des. Affen nehen dem Schliessen und öfnen des Mundes und der Augen nur zu zweierlei Bewegungen eingerichtet, näılich zu der des Zühnefletschens, welche der Affe mit allen-Fleischfressern gemein hat,' und zu der dos Maulspitzens, welche ibm wohl ganz eigen- 

thümlich zukommt. Hierbei ist nun nicht zu überschen, dass nicht allein die erstgenannte Bowegung erst durch die Mitwirkung des in dem Mundwinke! endenden Theiles des Hals- und Gesiehtshautmuskels vollstïndig gemacht wird, sondern dass auoh dieser Muskel überhaupt nit den beiden jene Bewegung horvorbringenden Muskelpartioen versohmolzen ist, und sie, zunnal die untere, bilden hilft; únd dass derselbe endlich einige Bündel selbst bis zu dem Schliesser des Auges in die Höho sehiekt! Es muss also die sehon an und für sich geringe Boweglichkeit des Gesichts bei dem Affen noch grossen Theils auf Rechnung der Halahautruukels kommen, was uns un wichtiger erscheint, wenn wir bedenken, dass dieser, al dem Hautrysteme angehörig wahl hauptsiichlich unter dem Einflusse der Rückenmarksperven steht; wenn auch allerdings bei dem Mensohen $Z$ weige von einigen Hirnnerven bis in die Haut des Halses eindringen. So glaube ich denn nicht mit Unreoht behauptem zu können, dass während die Gesichtsmuskeln dos Menisehen durch ihre freion und mannizfaltigen Bewegungen treue Verkündex des Saelenzustandes sein können, die des Affen nur zu wenigen, gemeinsamen Bewegungen befahigt, und dabei gleichsam in dem Hautsysteme untergegangen sind. Das Hautsystem ist überhaupt ale deckender und sehützender Apparat. bei den SäuRethieren mehr entwickelt als bei dem Ménschen, bei welchem dasselbe dagegen mehr zum Gefühìsorgan 

goworden ist; bei ersteren finden sich daher auch die Bewegungworgane der Haut, die Hautmuskeln, stärker auggebildet, während der Mensch derselben weniger bedarf. So soheint mir llenn ein wesentlicher, hier beiläufig zu erwähnender Unterschied dew Affen von dem Mensehen zu sein, dass ersterer nicht nur den Halshautmuskel mit dorn sogenannten Gesichtshautnuskel schr stark entwickelt zeigt, vondern auch einen dêm Menschen ganz abgehenden Bauchhautmuskel besitzt. Von dem OrangUtang wird swar behauptet, dass sich bei ihm auch kein Bauchhautmuskel findo indessen seheint mir derselbe zu wesentlich zu einem behaarten Felle zu gehören; als dass ich diese Behauptung nicht bezweifeln sollte, zumal dieser Muskel, wenn er wehwach' ist, leicht mit dem Behufs des Ausstopfens geschonten Felle entfernt wird. Von diesem Muskel scheint mir übrigens noch benerkenswerth, dass er bei demadfen an seinem vordern Ende in -eine regelmässige Sehne übergeht, und mit dieser an dem Oberarmknochen inserirt, was bei andern Thieren nicht der Fall zu sein pflegt, und wonach dem Arme des Affpn das Vermögen cinen gewissen Einfluss auf die Haut des Rückens auszuüben zukommeen muss. Als zu den Hautmuskeln gehörig, oder wenigstens nahe mit ihnen verwanit sind wohl auch die auf der Schälleldecke sich in die galea aponeurotica inserirenden Muskeln zu betrachten, und es scheint daher mit jener stärkern Entwicklung des 



\section{$-58-$}

Hautsystems bei dem Affen überhaupt zusammenzuhängen, dass anch diese Muskeln, namentlich die Bewger des hussern Ohrs (11. No. 1, 2, 4) so strirk ausgebildet sind, daher die galea mit einer Muskelschicht ganz überzogen und die hopfhaut schr beweglich erscheint; ganz besonderwscheint kngch einer Erwähnung:zu vendienen, dass der m, frontalis beidem Affen die Kopfhaut stark nach vorne rieht, whihrend er bei dem Menschen, mehr.Beweglichkeit in sich selbst hesitzend und weniger auf die galea wirkend; hauptsitchlich nur die Haut auf der Stirne und dem obern Augenhöhlenrande, und die in dicser haftenden Augenbraunea beiregty und Whidurch zu dem Ausdrucke des Gesichts. wesentlich beitrïgt Soviel von der-Versohiedenheit des Affen von dem Menschen in Hinsicht auf das Autlitz.

Dic Sprache ist unleugbar melir ein geistiger als ein korperlictier Vorzug des Menschen zu nennen, da sie nicht hlos als lie Fühigkeit, mannigfaltige articulirte Töne hervorzubringen erscheint, sondern als die, mittelst solcher Tone, welche erst durch conventionelle Festsetzung eine bestimnte Bedentung erhaten faben, dé verschicdensten Regungen der Seele den Mitmenschen kund zu thun; betrachten wir dieselbe aber, unserm $Z$ wecke genilss, nur von der körperlichen Seite, so kônnen wir sie nur von der besondern Organisation und Action der Muskeln des Kehlkopfs, der Zunge, des Gaumens und der Lippen herleitei. und tinden sie eben hr 

dureh von der Thierstinume unterschieden, welche letytere hauptsächlich nur auf höherer oder geringerer Lntwickelung der Lungen,; und besonderer Gestaltung der Luftröhre und ales Kehlkopfs beruht. Deahalb: köunen dic Vögel, ,abei denen Athmung und Stimme an allerhöchsten entwiokelt sind, unter allen Thieren um leichtesten einzelne Sprachlaute des Meuschen nachahmen, immer aber wird auch bei ithen diese Nachahmung wehr unyollkommen blcilien müssen," weil sie die Muskeln der Lippen, wdes Gaumens und der Zunge theils ganz entbehren, theils nur sehr düftig ontwiekelt tesitzen. Nach dem Gesagten kann es mir durchaus nicht in den Siun kommen zu bezweifeln, dass der Afle, 'wenn er das geistige Leben des Menschen besitise, dasselbe auch durch eine meinen Organen angemessene Sprache kund thun würde; aber dass eine solche Affensprache dinn der menschlichen durchaus unihulich scin müsste, und rlase der Affe bei geinem soust so grossen Nachahmungstriebe doch unfähig sei, mensch. liche. Worte nachzuplappern, will ich : darznthun versurheu. Von den bei den meisten Affen zwinchen demiz Zungenbeine und den Schildknorpel vorkommenden Luftsacke, welchen ich bei einem männlichen Cynocephalus bis zu dem Durchmesser von vier Zollen ausdehnbar gefundeu habo; und welcher ganz gewiss die . Stimme bedeutend verändern und schwächen muss, so wie von den Verschiedenheiten, welche sich in den IKnorpeln und Bän- 

dern des Kehikops finden, und welche Brandt sehr genau beschrieben hat, habe ich hier, als ausser meinem Gegenstande liegend, nicht zu redell. Die, eigenthümlichen Muskeln des Kehlkopfs aber, welche hier einer Betrachtung zu unterwerfen wären, zeigen sich nach meiner Untersuchung (IV: Nr. 11.) nicht wesentlich von den monschlichen verselieden, denn dass ich dio Boweger des KehIdeckels nicht auffinden konnte lag vielleieht nur an individueller Schwachheit derselben; die geringeren Abweichun* gen aber, welche ioh an den vorhandenen Muskeln wahrgenommen habe, werden erst dann gewurdigt werden können, wenn man die einzelnen Theile des Kehlkopfs mach dom trefflichen Vorbilde J. Müller's ganz zu deuten gelernt haben wird. Sonach bleiben mir nur die mehr in Allgemeinen den Sprachorganen diependen Muskeln zur vergleichenden Betrachtung übrig. Wenden wir nun zunächst unsern Blick auf die Bewegung des ganzen Kehlkopfs und des Zungenbeins, so finden wir erstens, dass bei dem. Affen der m. sternothyreoideus und der m. sternohyoideus (IV. Nr. 1,) wenigstens an ihrem hintern Theile ganz mit einander verwachsen sind, mithin Zungenbein und Kehlkopf der Bewegung nach dem Brustbeine hin, wenn sie irgend bedeutend ist, immer gemeinschaftlich Folge leisten müssen; wir sehen zweitens, dass der m. hyoglossus und der m. hyothyreoideus (IV. Nr. 3.) beim Affen nur einen - Muskck ausmachen; dass mithin das Zungenbein 
nicht für sich allein sein Ortsverhältniss zur Zunge oiler zum. Keblkopfe veriindern kann, sondern an der Bewegung jener beiden Antheil nehmen muss; wir finder endlich drittens die selbstständige Beweglichkeit des:Zungenbeins noch sladurch bedeutend verringert, dass der m, digastricus, nach sciner unter IV. Nr: 4, beschriebenen Bildung, keine unmittelbare Wirkung auf dasselbe ausüben kann, sondern nur daxu dient, theils den ganzen Unterkiefer herabzuziehen und den Mund zu offnen, theils mit dem m. mylohyoilleus (IV. Nr. 6.) gemeinschaftlich eine feste Grundlage für Zunge und Mundhöhle überhaupt abzugelsen. Wenden wir uns ferner zur Betrachtung der Zunge und der die Mundhöhle begrïnsenden Muskèn, so finden wir erstens, dass nicht allein die Zunge beim üussern Anblicke lang, platt, eckig und steif erseheint, soridern dass auch der m. genioglossus (IV. Nr, 8.) sich fast der ganzen Lange nreh in ihre untere Fläche einsenkt, dass fernex dieser Muskel so wie der m. hyoglossus und m. styloglossus (IV. Nr. 9.) sich tief in die Zungensubstanz hinein verfolgen fassen ohne Weine Wormischung ihrer gegenseitigen Muskelfasern zu zeigen, und dass mithin die Zunge wohl die Hauptbewegungen gleich der menschlichen ausüben kann, aber viel weniger Beweglichkoit in sich selbst besitzen muss; wir bemerken dann zweitens, dass sowohl der m. subcutaneus colli als der m. buccinator $\left(1 I_{*}: N_{*}, 12\right.$.) sich auf der Backentasche 

in ihre cinzelinen Mụskeflindel nuffossen und an derselben grossentheils ohne festen Insertionspunkt endigew, and dass mithin die Mnndhöhle les Affén bei weitem weniger fexte Seitenwandungen besitzt als dio des Menschen; wir sehon dam Irittens, dass das Gaumensegel mitrseinen Muskelnsnur unvollkommen-nugehildet; die uvila ganz verkimwert und mit keinem Muskel versehen, und dor m. pharyngopalatinus (IV. Nr. 14.) gar nicht als hinterer Gaumenbogen rw Gesicht komme vind dass mithindie Munilhöhle des Affen auch nach hinten hin nicht so vollkommen begränzt ist als dio des Mentchen, wif sehen endich viertens, wass das selbe nuch hinsieht der vordern Begränubg der Mundhöhle stattindet, indem der m. orbioularia oris (II. Nr. 10.) nur schwach entwickelt, mithin die Lippen nur wenig fleischig sind. Hiernach schelnen mirs Mangel an selbststindiger Beweglichkeit des Kehlkopfs und des Zungenbeins, zu geringe efgentliimliche Beweglichkeit der Zunge, Mangel an don durch dio Wangenmuskeln" añzútellenden fes. ten Seitenwandungen fer Mundhöhle, unvollkommene Bildung sos trothen Gaumens, und endlich zu schwachic Entwicklung des . Lippenschliessers Umstinde zusein, welcho zur Genüge darthun, diss der Affenicht zur menschlichen Sprache organisirt seic -

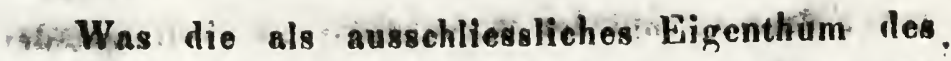
Menschen zu betrachtende aif rechte Stellung betriff, 



\section{$-63$}

wast schon lingst und von verschiedenen Seiten her der Rewelses gefiilurt worden, dass der Affe, wean er auch die Fahigkeit zeigt, sich auf seinen hinteren Extremitaten cinigomassen aufurichten nntsmit ihrer alleiniger Hulfe oiterzubcwegen, deminoch von der. Natur nicht zum aufrechten Cange, sonderu zu dem auf allen vier Extremititen lestinumbei; aber dieser Beweis ist bisher fast ledig. lich aus dem Baus dea Knochengeriistes des Afien, und aus der Vergleichung dessellien mit dem les Menschen van der einen und dem der vierfüssigon Thiere von dem anderon Seite liergonommen worlen. Es scheint mir daher nicht iiberfliissig zu sein, hier in aller Kürze anis der olien gegebenen Beschreibung der Muskeln des Aften diejenigen herauszuliebeñ und zusammen zu stellen welohs denselben als hicht zum aufrechten Gange organisirt erkennen lassen.

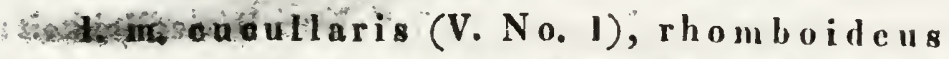

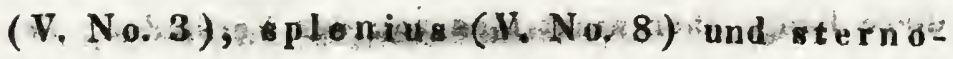
cteido m as to ide us (III.Non. 1). Bei den auf vier Füssen gehenden Thieren wïrde das Gesicht ganz gegen den. Eruboden gerichtet sein, wenn nicht das Hinterhauptslonh, nuthin die Vérbinlung des Kopfes mit der Wirbelsiule bei ihnen nehr nach hinten gerückt wäre als bei den Menschen; dalurch gewinnt aber der vordere Theil des Kopfes noch mehr. das Uebergèwicht nach vorne als bei dem letzteren, bẹi welchen dor ganze Kopf fast in der Schwebe steht; deshalb nom müssen dic Nackenmuskelu bei 

den vierfüssigen Thieren durch besondere Stäke oder durch eigentlü̈mliche Anorinungen in ihrer Action unterstützt werden. Hiernach ist es zu erklären, dass die genannten Muskeln beim Affen nicht allein verhältnissmässig stärker beim Menschen sind, sondern sich auch so hoch oben an jene Querleiste des Hinterkopfes ansetzen, welche hinsichts dex Insertion eben dieser Muskeln zwar der menschlichen linea semicircularis superior ossis occipitis analog ist, im Uebrigen aber ganz von ihr abwoicht, da sie theils sehr stark hervorspringt, theils ganz an den vorderen oder oberen Rande des Hinterhauptes liegt.

2. m. longissimus dorsi (V.No.10), splenius (V. No. 8), cervicalis désendens $(V$. No. 11), und trachelomastoidous (V. No, 12). Die aufrechte Stellung des Menschen gewährt auch seinem Haunte die grósntmöglichste Bewcgliclukeit; diese hängt alber nicht blos von der Verbindung des Kopfes nit deru Atlas und Epistropheus, sondern ganz besonders von der freien Bewegung des Halses ab; deshall ist der Hals bei dem Menschen am freistep bewegliohs whrend seine Beweglichkeit bei den vierfüssigen Thieren im Allgemeinen (die langhalsigen, den Kopf hochtragenden machen eine Ausnahme) beschränkter und glèichsant in der Streckung untergegangen exscheint. So finden wir, denn bei dem Affen wie bei den meinten Quadruperlen den langen Rückenmuskel zugleich den queren Nackenmuskel 

darstellend, len riemenförmigen Muskel des Halses fast, gany in lem des Kopfes untergegingen und nur durch eine Zacke desselben angedentet, endlich den absteigenden Nackenmuskel und den Nackenwarzenmuskel nur sehr schwach ausgebililet.

3. m. serratus anticus major (VI. No. 5), levator scapulae (V. No. 5), rhomboideus (V. No. 5) undacromio-basilaire (V. No. 4). Da bei dem Gange auf vier. Füssen dic vorderen Extremitäten einen grossen Theil der Körperlast zu tragen haben, muss: das: Schulterblatt bei den Quadrupeden mehr befestigt sein nls bei dem Menschen, und namentlich muss verhindert werilen, lass dasselbe nicht $z u$ sehr nach oben gedriickt, oder, zumal beim raschen Laufen und Springen, nach hinten geschoben werde. Dem gemäss sehen wir bei dem Affen wie bei den meisten Quadrupeden, namentlich den reissenden Thieren: den grossen vorleren $\mathbf{S i i -}$ genuskel sehr stark und mit dem Aufheber des Schulterblatts verbunden, so dass er hauptsächlićh das Ausgleiten des Schulterblatts nach oben, zugleich aber auch mit dem Aufheber zusammen las nach, hinten, ynd, da ex zum Thail von hinten herkommt, auch das nach vorne verhindern kann; ferner den rautenförmigen Muskel selbst weit nach vorn reichend und ausserdem mit einem besonderen, bei dem Menschen nicht vorhandenen Theile versehen, welcher an dem Hinterhaupte inserirt; endlich einen eigenthünlichen Heber oder Vorwärtszieher des 



\section{$-66-$}

Schulterblattes, der bei allen vierfiissigen Thieren, dagegen bei dem Menschen' gar nicht gefunden wird.

4. m. rectus abdominis (X. No. 4), und mm. obliqui abdominis (X. No, 1, 2). Bei dem Gange auf vier Füssen ruht die Last der Bancheingeweide fast lediglich auf der vordern Bauchwand, welche deshalb besonders befestigt sein nuss; es geschieht dies aber hauptsïchlich durcli den querLaufenden und den geraden Bauchmuskel, und zwar hinsichts des letzteren mit dadurch, dass er sehr weit nach vorne an der Brust inserirt; so finden wir denn denselben bei Ratuhthieren bis zum vordern Ende des Brustbeins, und beridem Affen wenigstens bis zur füften Rippe reishend. Bei dem aufrechten Gange dagegen drücken die Eingeweide hauptsüchlich auf das Becken, zum Theil aber auch auf den untern, durch die hreiten Bauchmuskeln gebildeten Theil der Bauchwand; es müssen daher bei dem Menschen die Behufs des Austrittes des Saamenstranges, der Blutgefisse und Her Nerven der untern Extremität nothwendigen Oeffnungen möglichst gesichert sein, was bei den vierfüssigen Thieren nicht in dem Grade nöthig ist; daher finden wir donn sowohl den Leistenring, als den Schenkelring bei dem Affen viel weiter geöffnet äls beim Menschen.

5. m m. glutaei (XIV. No. 1, 2, 3), pyriformis (XIV. No.4), gemini (XIV. No.6.) und quadratus feinoris (XIV. No. 7). Bei dem Menschen wird nicht nur das Gehen durch eine 

trehende Bcwegung des Beckens begünstigt, sondern es gewinnt auch der ganze Körper beim Aufrechtstehen dadurch an Festigkcit, diss die Oberschenkel, und mit ihnen die Fusse nach ausen gedreht sind; deshalb sind bei dem. Menschen die Rollmuskeln des Oberschenkels stark entwickelt, wihrend das Thier bei dein Gehen auf vier Fiissen derselben weniger bedarf. Demgenäss rollen die Gesiissmuskeln und der viereckige Schenkelmuskel bein $\Lambda$ ffen Jen Oberschenkel gar nicht, sondern heben ihn nur nach hinten in die Höhe, und von den eigentlichen Rollmuskeln sind lie nambaft gemachten nur sehwach entwickelt.

6. m. Iatissimus dorsi (V. No.2) und subcutaneus abdominis (I. No.2). Beim aufrechten Gange bedarf der Arm in der Regel keines herabziehenden Muskels, da er Jurch seine eigene Schwere abwäts sinkt; der breite Rückenmuskel tritt daher bei dem Menschen nur in dem Falle in Thätigkeit, wenn entweder die obere Extremität eine Hemmung erleidet, oder wenn bei Befestigung derselben der Rumpf gegen diese hingezogen werden soll; viẹl bestïndiger wird lagegen die Action dieses Muskels bei den vierfüssigen Thieren in Anspruch genonmen, da die Rürkwirtsbeweğung des Vorderfusses, namentlich beim Gehen, grösstentheils lurch ihn bewirkt wird. Bei dem Affen finden wir nun aber den, Latissimus dorsi nieht allein stark, sondern noch mit einem zweiten Kopfe, oder einem 

besonderen Muskel versehen, welcher von seiner Sehne zu dem Ellenbogenhöcker heraligeht. Ich möchte vermuthen, dass dieser Muskel ganz besonders bei dem Vorneiberwerfen des an den vordern Extremititen hilngenden. Körpers in Thittigkeit tritt, welche Bewegung bekanntlich von den Affen so geschickt ausgeführt, dem Mensehen aber nur mit grosser Anstrengung und nach mehrmaligem Hin- und Herschwenken des Körpers möglich wird; denn wenn der Affe z. B. mit den gestreckten vordern Extremititen an einem Baumaste hängt, und sich vorne ülerwerfen will, wird er den breiten Rückenmuskel wirken lassen, flectirt er nun den Arm, und spannt er damit zugleich jenen zweiten Bauch des Latissimus an, o muss dieser letztere nach vorn gezogen und dadurch bedeutend in seiner Wirkung unterstützt werden. Noch ist zn erwühnen, dass bei dem Affen der breite Rückenmuskel auch durch den, ihm nicht gan\% unahnnlichen Bauchhautmuskel in seiner Wirkung einigermassen unterstützt werden muss.

7. m. gracilis (XIV. No. 8), sartorius (XIV. No. 9), biceps femoris (XIV. No. 15) und semitendinosus (XIV. No. 16). Dass diese Muskein beim Affen wegen ihres sehr tiefen Ansatzes und gespannten Aussehens der vollkommen Streckung des Kniegelenks im Wege stehen, ist bereits bei ihrer Beschreibung erwihnt worden, und sie können demnach bcweisen, dass der Affe wenig- 

stens zum vollkonmen aufrechten Gange nicht organisirt ist.

8. Dic männliche Ruthe des $A$ ffen hat eine mit der der Quadrupeden mehr als mit der des Menschen übereinkomniende Bildung und Stellung, ist nur zu der den vierfïssigen Thieren eigenthümlichen Weise der Begattung eingerichtet, und deshall, auch mit von der mensehlichen Bildung sehr abweichenden Muskeln versehen, deren Beschreibung bereits unter XII. No, 1, 2 gegeben und hier nicht zu wiederholen ist.

9. Endlich möchte wohl đer Besitz eines Schwanzes als nicht mit dem aufrechten Gange vereinbar zu betrachten sein, und es ersclieint daher bemerkenswerth, dass auch die sogenannten ungeschwinzten Affen, wenn auch die Anzahl ihrer Schwanzwirbel nicht die unsrer Steisbeinstiicke übertrifft, dennoch eigentlich einen Schwanz besitzen, da diese ihre wenigen Schwanzwirbel mit allen cinem langen Schwanze zukommenden Muskeln (mit Ausnahme eines Seitwärtszichers, den ich bei Inuus nicht gefunden habe) versehen sind.

Wir kommen jetzt in unsrer vergleichenden Betrachtung zu dem vierten Vorzuge des Menschen vor den Thieren, «u dem Besitze der Ilinde. Diesen Vorzug hat man aber bisher dem Menschen noch micht vollkommen zucrkannt, da man dis Geschlecht der Affen mit dem Namen Quadrumanen belegt, mit- 

hin denselben sogar in dieser Beziehung den Vorrang vor dem Menschen eingerüumt hat, indem ja doch offenbar lie Hände auf einer höhern Stufe der Organisation stehen als die Füsse. Man schreibt allgemein den $\mathrm{Affen}$ den Besitz von wirklichen $\mathrm{H} \ddot{\text { än- }}$ den deshalb zu, weil man das characteristische Merkmal einer Hand allein in dem entgegenstellbaren Daumen : finden zu müssen glaubt. Dass dies ein Irrthum ist, dass zur Darstellung einer menschenahulichen Hand mehr Figenschaften erforderlich sind, als der blosse Besitz eines entgegenstellbaren Daumens, und dass dem Aften diese Eigenschaften grösstentheils abgehen, derselbe mithin keine Hand besitzt, will icli darzuthun versuchen; und da dieser Gegenstand, soviel niir bekannt ist, noch nirgendswo zur Genüge erörtert ist, erlaube ich mir auf denselben niiher eingehend hier selbst von meinem eigentlichen Thena etwas abzuschweifen.

Es scheint mir zunïchst nöthig, den Unterschiell zwischen Fuss und Hand in Allgemeinen festzustellen; dies kann aber nicht ohne die Betrachtung der ganzen, dem einen wie der antern zugehörigen Extremität geschehen.

Betrachten wir zuförderst die Verrichtungen unsrer Glieflmassen, von deren organischen Baue ganz abstrahirend, so finden wir, dass ler Hauptzweck der obern Extremititen in Adtraction, der der untern Extremititen in Repulsion liesteht; mittelst ersterer nähern wir fremde Gegenstände unsrem 
Körper, oller ziehen in selteneren Fïllen unsren Körper zu einem andern, festen Gegenstande hin; durch letztere dagegen stossen wir entweder fremde Gegenstände von uns weg, oder suchen im gewöhnlichern Falle unsern Körper durch Abstossen von einem festen Gegenstande fortzubeweren. Dies gilt durchaus nicht blos für obere und untere Extremitäten des Menschen, sondern findlet auch auf die vordren und hintren Gliedmassen aller vierfüssigen Thiere Anwendung. Am deutlichsten können wir uns lavon überzeugen, wenn wir den Gang eines Thieres unter irgendwie erschwerenden Verhältnissen beobachten; läuft" z. B. ein Pferd bergan, so greift es mit vorgestrecktem Vorderfusse möglichst tief in den Erdboden ein, um an diesem Punkte festhaltend durch Contraction der Vorderextremitäten den Körper empor zu ziehen, und gleichzeitig trift es mit nach vorn gebogenem Hinterfusse fest auf, um durch Streckung dieser Extremitit den Körper von dem betretenen Punkte ab nach vorn guschieben. Nur auf diesem Heranziehen mittelst der vordern, und dem Vorwärtsschieben mittelst der hintern Extrenitäten kann der Gang der vierfïssigen 'Thiere beruhen, da bei ihnen nicht so wie bei den Menschen eine veränderte Lage des Schwerpunktes des Körpers, und eine Irehende Bewegung des Beckens mit in Betracht komint.

Dasselbe Verhältniss zeigt sieh auch bei Verrichtungen, bei welchen der thierische Körper als 

fester Punkt erscheint. Will z. B. cin Hund ein Loch graben, so scharrt er mit den Vorderfüssen lie auszugrabende Erde zu sich heran, und wirft dann die bereits ausgescharrte mittelst der Hinterfüsse hinter sich fort. Die meisten vierfüssigen 'Ihiere ziehen ihre Nahrung oder ihre Beute mit den vordern Extremitäten zu sich heran, oder sie erfassen in Kanpfe ihren Feihd mittelst derselben, um ihn in das Bereich ihrer Hauptwaffe, gewöhnlich der Zähne, zu bringen; selbst das Pferd, bei dem die Vorderextremität an weitesten von ler Organisation ler Hand entfernt ist, scharrt das etwa zerstreutliegende Futter mit dem:Vorderfusse heran, und wenu es im Kampfe begriffen, gebraucht es den Vorderiuf nicht um deq Feind von sich abzuhalten, denn in diesem Falle kehrt es sich un und braucht die Hinterhufe, sondern wenn es von Kampflust beseelt selbst angreift, und zwar in der Absicht, den Gegner unter sich zu bringen.

Ist nun Heranziehen ler Hauptxweck der obern oder vordern Extremität, dagegen Abstossen der der untern oder hintern, so muss auch nothwendig die Hauptaction der ersteren in Beugung, die der letrteren in Streckung bestehen. Streckung nenne ich hier, abgesehen von der Form der einzelnen Gelenke, diejenige Bewegung, bei welcher das Glied die grösstınögliche Längendimension einnimmt. Dass jeder Streckung eine Beugung, und jeder Flexion eine Extension vorauggehen müsse, versteht sich 

von selbst, es ist aber zu unterscheiden, wclche von diesen beiden den zu erzielenden Effekt hervorbringt, wclche dagegen das Glied nur in die I.age versetzt, von welcher aus die cffektuirende Bewegung mit Erfolg stattfinden kann. Wollen wir z. B. irgend einen Gegenstand zu uns heranlangen, so müssen wir allerdings zuerst unsre Hand nach diesem Gegenstande ausutrecken, aber es ist dinn diese Streckung nicht effektuirend, sondern nur vorbereitend, indem das Heranlangen nur erst durch die darauffolgende Beugung erzielt wird. - Der obige Satz gilt nun in Betreff der untern oder hintern Extremitäten ganz, allgemein. Bei den 'Thieren wirken die Hinterfüsse nicht allein bei ler Ortsbewegung des Körpers, sondern auch bei jeder andern ihnen etwa obliegenden Verriohtung lediglich durch Strekkung; so gebrauchen z. B. die Einhufer ihre hintern Extremitäten als Waffe, aber ihr sogenanntes Ausschlagen ist nichts, andres, als cine vorbereitende Beugung der Hinterfüsse, auf welche eine rasche und kraftvolle Streckung folgt. Wenn der Mensch im Stande ist, einen Gegenstand mittelst ler Füsse zu gich heranzuziehen, oder wenn er bei gymnastischen Uebungen den an den Füssen hüngenden Körper durch Beugung der untern Extremitäten in die Höhe z.u heben vernag, oder wenin ein ohne Arme Geborener mittelst der Füsse Verrichtungen der ihm fehlenden Gliedmassen ausïben kann, so müssen wir alles dies doch nur als ungewöhnlich, und ausser 



\section{$-74-$}

der Bestimnung unsrer Fïsse liegend betrachten, da dieselben beim Gehen, Laufen, Springen, Schwimmen u. s. w. immer nur durch Extension wirken.

Dass ferner die Haupiaction der vorileren Extremititen in Flexion bestehe, hat für die vierfüssigen Thiere wenigstens so aligemeine Gültigkeit, dass mir ausser der Bewegung beim Aufstehen kaum irgend eine Verrichtung bekannt ist, welche bei denselben durch Fxtension der Vorderfüsse erzielt wiirle. Kein Thier stösst nuit den Vorderextremitäten einen Gegenstand von sich ab; will es dies, so bedient es sich entweder der hintern Extremitiiten oder des Kopfes. Schen wir etwa das Thier beim Bergablaufen oder bei denı sogenannten raschen Barriren durch vorgestreckte Vorderfüsse seinen Iauf hemmen, so ist dies nur eine passive lixtension, kein Ausstrecken, sondern ein Gestreckthalten.

Anders aber verhailt sich die Sache bei lem Menschen; obgleich auch liei ihm Ailtraction unbezweifelt der Hauptzweek der obern Extremität ist, so ist dieselbe doch fast eben so häufig duroh Extension als durch Flexion thätig. Eben so gut als wir mittelst der Hainde Gegenstiinle zu uns heranziehen können, eben so gut vermögen wir sie mittelst derselben wieder von uns zu stosson, und nur wemn wir stiirkere Gewalt anwenden, oder das Gefült von Abscheu und Verachtung ausdrïcken wollen, nehmen wir.dlahei die Füsse zn Hülfe. Wir können ferner ein und dieselbe Verrichtung häutig 

ebensowohl durch Streckung als durch Beugung vollführen, so x. B: die obere Extremitüt als Waffe gebrauchend, ebensowohl durch rasche Extension, als durch rasche Flexion des Armes und der Hand Schläge austheilen. Rär, Katze, Affen nnd andere Thiere vertheidigen sich auch gegen ihre Feinde indem sie mit den Vorderfüssen schlagen, aber dies geschieht immer so, dass sie zuerst die Extremität strecken, "und dann eine rasche Beugung folgen lassen, bei ihnen hat daher immer der Schlag eine Richtung naoh ihreni eignen hörper hin.

Die adtractive Thätigkeit der obern oder vordern Extrenitait erscheint erst dann vollstïndig, wenn sie mit einem wirklichen Erfassen des heranzuziehenden Gegenstandes verbunden ist. Zu dem Erfassen ist es nöthig, dass eine Kraft von mindestens zwei einander entgegengesetzten Punkten her auf einen Gegenstand einwirkt, und dieses zu leisten ist die Hauptfunction der Hand. Das Erfassen geschieht zunächst durch Beugung der Fingerglieder, und wird um so vollkommner sein, je lïnger diese Glieder sind; es wird ferner um so sicherer sein, je grösser der Flichenraum ist, welchen die gebogenen Finger beherrschen; deshalb tritt zu jener Flexion eine zweite Bewegung hinzu, nämlich die des Spreizens oder Abducirens der Finger. Die flectirten Fingerglieder können nur verhältnissmässig kleine oder dünne Gegenstände von zwei entgegen- 

gesetzten Seiten berühren, es wirl daher die Beugung und Spreizung derselben durch eine dritte Bewegung unterstützt, welche: wir das Entgegenstellen oder Opponiren eines oder zwcier Finger nennen. Wo das Glied nach seiner Organisation, diese dritte Bewegung zu leisten nicht im Stande ist, oder wo das Opponiren einzelner Finger bei sehr grossen Gegenstünden: nicht ausreicht, da müssen die beiderseitigen Fxtrenitïten einander zu gemeinsamen Dienste entgegenkommen. Da das Erfassen um so sicherer ist, je enger sich die Hand an den Gegenstand anschliesst, so koınmt, zumal für kuglige Gegenstände, noch eine vierte Bewegung hinzu, nämlich das Hohlmachen der Hand. Alle diese Bewegungen werden am vollstilndigsten von der menschlichen Hand vollführt, und namentlich ist die zulletztgenannte nur bei dieser von einiger Bedeutung; die menschliche Hand ist mithin zum Umtassen am vollkommensten organisirt. Bei den Hufthieren kann, wo die adtractive Thätigkeit der vordern Extrenitaten auf Fortbewegung des Körpers gerichtet ist, das Erfassen nur durch festes Auftreten und möglichst tiefes Eingreifen in den Erdboden einigermassen ersetzt werden, und wo dureh dieselbe fremde Gegenstände dem Körper genähert werden sollen, kann die Extremitit nur gleich einer Schatufel wirkend den Gegenstand heranschicben. Bei Raubthieren und Nagern werlen die Beute oder sonstige Gegenstände schon crfasst, aber es vermag dies 

nicht eine lixtremität allein, sondern es miissen die beiderseitigen Extremititten einander entgegentretend zusammen wirken. Die Beutelthiere, Makis und Affen dagegen, deren Vorderextremitäten sich der Organisation der menschlichen Hände nähern, kön. nen schon mässig grosse Gegenstände mit einer Extremität unfassen, und zu sich heranziehen.

Der Fuss ist nicht wie die Hand zum Erfassen organisirt; er besitzt statt dessen nur das Vermı̈gen, sich dem betretenen Boden einigermassen anzuschmiegen, und dadurch fester zu haften. Dies gilt für die Menschen sowohl wie für die T'hiere; 'jedoch wird bei denjenigen unter letzteren, welche von der Natur angewiesen sind, auf unebenem und unsicherem Borlen sich zu bewegen, dieses Vermïgen des Anschmiegens bis zum. Festhalten gesteigert, und es erhält dann der Fuss einige Aehnlichkeit mit der menschlichen Hand; so namentlich bei den Affen, die den grössten Theil ihres Lebens auf den Bäumen zubringen.

Die mittelst der vordern Gliedmassen zu erfassenilen und heranzuziehenden Gegenstïnde muissen nothwendig einen geringeren Widerstand leisten, also minder schwer sein als der Körper selbst, denn im entgegengesetzten Falle würde bei der Wirkung der Beugemuskeln nicht der fremde Gegenstand gegen den Körper, sondern umgekehrt dieser gegen jenen gezogen werden. Der Mensch selbst vermag durch die Arme nur dann das Gewicht seines eige- 

nen Körpers nach einem Anhaltspunkte hinzuziehen, wenn entweder die Füsse oiler das Uebergewicht des Körpers zur Forthewegung beitragen, oder wenn das Medium, in welchem der Körper sich lefindet $z$. B. das Wasser ihm einen, Theil seines Gewichtes benimmt, oder endlich wenn durch hïulige Uebung die Beugemuskeln der Arme eine mehr als gewöhnliche Stärke orlangt haloen. Im Allgemeinen steht gewiss fest, dass die obern Gliedmassen nur Icichtere Lasten fortzubewegen bestimimt sind, als die des Körpers selbst. - Anders verhält es sich mit den untern Gliedmassen. Bei der Thitigkeit "dieser ist in der Regel der, thierische Körper selbst der zu bewegende, ler Erdboden der feste Punkt; und wenn wir nun bellenken, dass der Körper häufig noch durch fremde Lasten beschwert lurch die Füsse weiterbewegt wird, so ergiebt sich, dass dic durch die Streckung der untern Extremitäten zu überwindende Last in der Regel schwerer ist als der Körper sellsst, dass mithịn die untern Extremititen durch grössere. Kraft vor len obern ausgezeichnet sind. Dies gilt nun wohl am meisten für den Mensehen, weniger für die Thiere, bei denen die Vorderextremitäten auch einen Theil der Körperlast zu tragen haben; indessen findet es sich doch auch hier bestätigt, und zwar um so mehr, je mehr die vordern Gliedmassen zum Erfassen organisirt sind. 

Der feste Punkt, von welchem alıstossend wir unsern Körper Hurch die untern lixtremititen fortbewegen, ist in der Regel der unter und hinter uns liegende Frdboden; diese Extremititen bediirfen daher zu ihrer Funktion hauptsächlich nur eine Richtung der Bewegung. Die durch die obern lixtremitäten heranzuzielienden Gegenstïnle dagegen sind theils an sich niannigfnltiger, theils liegen sie in den verschiedensten Ebenen; es müssen daher diese Extremitäten nach verschiedenen Richtungen hin wirken können, das heisst beweglicher sein. Diese grössere:Beweglichkeit fler obern oder vordern Extremitäten wird hauptsiichlich durch das Vermögen zu erfassen bedingt, denn dieselbe wird bei den Thieren, welchen wie den Pachydermen und Wiederkăuern dieses Vermögen abgeht, auf das minimum reducirt.

Die Normalstellung der vordern Extremitiit bei allen auf vier Füssen gehenden Thieren ist die, bei weicher der Riicken der Hand nach vorn und oben, die Hohlhand nach unten und hinten gekehrt ist, eine Richtung, welche wir mit dem Namen Pronation belegen.. In dieser Richtung verharrend wire es dem Thiere nür niöglich, einen Gegenstand $x_{0}$ B. einen Stab zu erfassen, wenn derselbe sich in horizontaler Lage befände; da nun aber viele zu erfassende Gegenstănde, wio z. B. die zu erkletternden Bäume, aufrecht stehon, so wird der Extremitit eine Bewegung nöthig, bei welcher die Hand so 

gerichtet ist, lass die Hohlhand nach innen, der Handrücken nach aussen sieht, eine Bewegung, welche wir bei dem Menschen, wo sie bis zur völligen Umkehrung gesteigert werden kanr, Supination nennen.

Die Ausdricke: Pronation und Supination, sowie Flexion und Extension bedeuten ebensowohl eine gewisse Richtung, als eine Bewegung nach dieser hin. Da bei den Thicren die Richtung der Pronntion die normale, die der Supination dagegen eine zum Erfassen aufrecht stehender Gegenstände nothwendig erseheinende Abweichung von jener ist, so glaube ich nicht zu weit zugehen, wenn ich bei ihnen die Supination als Bewegung betrachtet eine positive, eine wesentlichere, die Pronation, als Rückkehr zur normalen Richtung, eine negative, eine untergeorlnetere Bewegung nenne, und sonach behaupte, dass bei den Thieren die Supination die hauptsächlichere Bewegung der vorilern Extremität sei. Anders verhält es sich bei dem Menschen. Wie bei ihn nach obiger Auseinandersetzung die vordere Extremität ebensowohl durch Extension als durch Flexion wirksam ist, so sind auch Pro- und Supination bei ihm von gleicher Bedeutung, denn er vermag die Hand ganz zu drehen, und ebensowohl deren Rücken als deren Volarflïche nach vorn oder nach hinten zu kehren; deshalb steht bei ihm in der Normallage die Extremitait in halber Supination und halber Pronation, wie sie aus obigem 

Grunde bis zu den Fingergliedern herab in halber Extension und halber Flexion steht.

Wie die ganze obere Extremitï des Menschen nicht blos Jurch Beugung ihre Thätigkeit zeigt, so ist auch deren äusserster 'Theil, die Hand, nicht blos zum Erfassen lestimmt, sondern vollführt die mannigfaltigsten Verrichtungen, von denen liei den Thieren nicht die Rede sein kann. Bei diesen, luei denen es nur aufs Erfassen, mithin nur nufs Beugen und Strecken, oder Schliessen und Aufmachen der ganzen Hand ankommt, bedürfen sümuntliche, oder wenigstens die vier iussern Finger nur einer gémeinschaftlichen Extension orler Flexion; bei der menschlichen Hand dagegen, deren Verrichtungen hïufig den verschiedenartigen Dienst einzelner Finger in Anspruch nehmen, muss nicht nur der Daumen, sondern auch jeder andere Finger eine selbststïndige, von den übrigen unablïungige Beweglichkeit lesitzen, so dass irgend ein Finger gebeugt oder gestreckt werden kann, während die übrigen die entgegengesetzte Bewegung verrichten.

Fassen wir das bisher Gesagte zusammen, eo können wir folgendle Siitze aufstellen: Die obere oder vordere Lxtremitiit unterscheidet sich von der unteren oder hinteren bei Menschen und vierfüssigen 'Thieren dadurch, dass

1. Heranziehen und Erfassen Hauptzweck der ersteren, Abstossen dagegen Hauptzweck der letztern; 

2. Beugung Hauptaction der 'erstern, lagegen Streckung Hauptaction der letztern; endlich

3. Beweglichkeit Hauptcharakter ier erstern, dagegen Festigkeit und Stärke Hauptcharakter der letztern ist.

Hinsichts des Unterschiedes der menschlichen Hand von der vorlern Extremitiit der Thiere ferner können wir feststellen :

1. Bei ersterer ist Beugung und Streckung fast ganz gleichnaissig entwickelt, während bei letzterer nur die Bcugung als effectuirende Bewegung erscheiıt.

2. Erstere ist am vollkommensten zum Erfassen organisirt, indem namentlich das Hohlmachen nur bei ihr einige Bedeutung hat.

3. Erstere ist am freisten beweglich, indem namentlich die Pro- und Supination bei ihr ganz gleichnässig entwickelt sind, wïhrend bei letzterer nur die Supination als positive Bewegung zu betrachten ist.

4. Bei ersterer ist jeder einzolne Finger ciner selbtsständigen Bewegung fähig, während bei letzterer höchstens nur der Daumen einige Unabhängigkeit zeigt, die übrigen Finger dagegen nur eiıcr gemeinsamen Beugung und Streckung fahig sind.

Eine verglcichende Betrachtung des organischen Baues der menschlichen Hand und des menschlichen Fusses wird uns nun die obigen Sätze bestitigt zeigen, nur dürfen wir uns hierbei nicht blos auf lie eigentliche Hand und den eigentlichen Fuss beschriilken, sondern müssen, da deren Bewegungen grossen 

theils von Iem Vorderarme und dem Unterschenkel ausgehen, diese Theile mit in Betracht ziehen.

Wenden wir uns zur Betrachtung des Knochenbaues, so treffen wir unterhalb des Knie- und lillenbogen-Gelenks bei dem Menschen auf zwei Knochen, von denen der eine, imehr nach innen gelegene der verhältnissmässig stärkere ist, nit dem Oherschenkel und respective Oberarm durch ein nur nach einer Richtung bewegliches Gelenk zusanmenhängt, und daher an dem Unterschenkel wie an dem Vorderarme den festen Punkt abgiebt; dagegen. Jer andere mehr nach aussen geleyene, gar nicht oder nur sehr lose mit dem Olierschenkel und respective Oberarn verbunden, der mehr bewegliche Theil des Untersehenkels und Vorderarms ist. Soweit kommit die untere Extremität mit der obern überein; unterscheidend ist aher; dass; da bei letzterer die Bewoglichkeit vorherrschend ist, die Hand fast ganz allein mit dem beweglichen Knochen, dem Radius, verbunden ist, der Fuss dagegen hauptsächlich mit dem festeren Knochen, der Tibia, zusammenhängt, welche Verbinding die bewegliehere. Fibula nur seitlich nach aussen gu vervollstïndigen hilft. L...? andere wesentliche Verschiedenheit zeigt sich darin, dass sish der Radius hall, um seine Axe drehen kann, wodurch, da die Hand seiner Bewegung folgen muss, die schon oben besprochene Pro-, und Supination hervorgebracht werden; an dem Fusse dagegen solche Bewegung, welche der nöthigen 

Festigkeit Abbruch thun wïrde, gar nicht stattindet, die Fibula fast ganz unbeweglich mit der Tibia verbunden ist, und nur ganz nach unten etwas von dieser abgedräingt werden kann, un vielleicht ler zerbrechenden Wirkung einer auf das Fussgelenk seitlich auftreffenden Gewalt einigernassen nachzugeben.

Gehen wir weiter abwärts, so treffen wir auf den sehr wesentlichen Unterschied, dass die menschliche Hand vom Vorderarme in gerader Richtung abgeht, der Fuss dagegen mit dem Schenkel in rechtem Winkel steht, und nach hinten nit der sogenannten Ferse stark hervorragt. Diese Einrichtúng des Fusses dient wohl eines Theils dazu, dem ganzen Körper einen hinreichenden Stützpunkt zu geben; sie ist aber ganz vorzüglich wohl bestimmt, die Hauptaction des Fusses, die Streckung nimlich, zu erleichtern und zu verstärken. Die Knnchen dienen bekanntlich bei der willkührlichen Bewegung als Hebel, und zwar in der Regel als solche, wel. che den Unterstützungspunkt an ihrem einen Ende haben d. h. als einarmige Helsel. Die Natur bedient sich nun dieser meistens um gine geschwinde und sehr ausgedehnte Bewegung hervorzubringen, und bringt deshalb die bewegende Kraft d. h. den Muskel ganz dicht an dem Unterstïtzungspunkte d. h. den Gelenke an. Bei der Streckung des Fusses komnt es nun alser nicht sowohl nuf eine schnelle, als auf eine kraftvolle, die Last des gan- 

zen Körpers überwiegende Bewegung an, es nuss deshalb nit der bewegenden Kraft gespart werien, und dies geschieht dadurch, dass dieselbe möglichst weit von dem Unterstützungspunkte angebracht wird. Nun könnten aber dic Streckmuskeln des Fusses, da sie denselben abwirts zu ziehen haben, wenn die Fussknochen als einarmiger Hebel dienen sollten, nicht anders zu einem von dem Hypomochlium entfernt licgenden Punkte gelangen, als. indem sie eine Strecke weit an der Fusssohle hin mit den Knochen parallel liefen; dadurch würde aber nichts an Kraft gewonnen werden, da nur die senkrecht auf den Hebel auftreffende Kraft von Beleutung ist; deshalb bedient sich die Natur der Fussknochen als eines zweiarmigen Hebels, an dessen einem, allerdings kürzerem Arme, der Ferse nämlich, die bewegende Kraft verhältnissmässig weit von dem Unterstützungspunkte angebracht ist. Hieraus erkennen wir, dass an dem Fusse offenbar die Strekkung schon durch den Knochenbau begünstigt wird, während-an der menschlichen Hand für Extensior. und Flcxion gleichmäissig gesorgt ist.

Von den Fusswurzelknochen dient nur cin einziger zur Gelenkverbindung mit dem Unterschenkel, von den Handwurzelknochen dagegen geht fast die ganze erste Reihe die Verbindung mit dem Vorderarme ein. Offenbar muss eine Verbindung, bei welcher der Gelenkkopf nur durch einen Knochen dargestellt wird, mehr Festigkeit durbieten, als eine 

solthe, bei welcher dassellie durch mehrere Knochen geschieht. Diese Festigkeit wirl nun an den Fusse noch durch den Uustand bedeutend vermehrt, diss die untersten Enden der 'Tibia und Fibula als milleolus internus und externus den Talus seitlich gauz fest umschliessen, während die ihnen entsprechenden processus styloidei des Rarlius und der Utna fast gar nicht zur Gelenkbildung beitragen. So ist denn an rlem Handgelenke neben der Beugung und Strekkung auch eine Seitenbewegung, eine Adduction und Abduction gestattet, und es entsteht durch deren Vereirigung ein freies Gelenk; an dem Fusse dagegen ist nur Extension und Floxion freigegeben, und wenn wir ausserlem im Stande sind, die Fusssohle etwas nach innen oder nach aussen zu kehren, so berult dies nur auf geringer Verschiebung der Fusswurzelknochen untercinander.

Von den Handwurzelknochen liegen je viere in einer Reihe neben einauler, und da dieselben mit Ausnahne eines einzigen mehr breit : lang sind, so muss nothwendig die ganze Handwurzel eine doppelt so grosse Breiten - als Längen-Ausdehnung haben. Da nun ferner diese einzelnen Knochen an ihrer untern, der vola manus zugekehrten Früche etwas schnäler sind als an der Dorsalfläche, nnd da sich die in einer Reihe liegenden fast durchgehends nur glatte Flachen zukehren, so bokommit nicht allein die Handwurzel im Normalzustande eine Wölbung von der einen Seite zur andern, sondern 

es kann auch dieselbe durch geringe Verschiebung der Handwurzelknochen bis zu lein sogenannten Hohlmachen der Hand gesteigert werilen, und es muss dieses Hohlmachen um so stïrker hervortreten können, je breiter die Handwurzel selbst ist. Ganz anders verhält es sich mit den Fusswurzelknochen, denn von diesen liegen nur die vier vordersten neben einander, die drei hinteren dagegen theils über, theils vor einander; auch sind sie sämmtlich, vorzuiglich aluer die beiden hinteren, mehr lang als breit, und es erseheint deshalb die ganze Fusswurzel verhältnissmässig schmal und in die Länge gezogen. Wollten wir für die einzelnen Handwurzelknochen die homologen Fusswurzelknochen suchen, so würden wir das os naviculare des Fusses, weil es mit den drei ersten Knochen der zweiten Reihe in Beriuhrung steht, dem gleichnamigen Knochen der Hand gleichsetzen, indem wir annehmen, dass dasselbe aus der Gelenkverbindung mit dem Unterschenkel verdrängt, mehr nach vorn geschoben sei; das os lunatum würde dann schr vergrössert dem Talu: entspreclíen, und als solcher allein den Gelenkkopf für das Fussgelenk abgeben; das os triquetrum würde, in dic Länge gezogen und abwärts gedrückt, durch den Calcaneus dargestellt werden; und von dem os pisiforme müssten wir annehmen, dass es mit denı hintern Theile des Fersenbeins verschmolzen das tuber calcanei bilde, wie denn dasselbe bei allen vierfüssigen Thieren stark nach hinten her- 

vorragt, und die Funktion der Ferse versieht. Die übrigen Handwurzelknochen wïrlen nach Lage und Verbindung ganz den vier vorderen Fusswurzelknochen entsprechen.

Was endlich die Mittelfuss- und Mittelhandknochen, und die Phalangen der Zehen und Finger betrifft, so kann uns bei deren Vergleichung eine Verschiedenheit hinsichts des Lüngenverhältnisses nicht entgehen. An der mensclulichen Hand bilden die Fingerglieder den lïngsten, die Handwurzel den kürzesten Theil, und die Mittelhand steht hinsichts der Länge zwischen beiden; an dem Fusse lagegen steht an Lünge die Fusswurzel oben an, dann folgt der Metatarsus, und die Zehenglieder nehmen die dritte Stelle ein. Da, wie wir schon oben erwähnt haben, die Knochen der Extremitäten als Hebel dienen, so muss, bei hinlänglicher Kraft, offenbar durch dieselben desto mehr effectuirt werden können, je länger sie sind; es muss also auch die verhältnissmässige Länge der Fusswurzel und des, Mittelfusses - die Zehen kommen hier nicht in Betracht, weil sie keine genügende Steifigkeit haben - geeignet sein, der Streckung der untern Extremitit mehr Erfolg zu geben; als Beleg dafür sehen wir, dass bei Thieren, bei denen durch Streckung der hintern Extremitäten der Körper schnell und weit fortbewegt werilen soll, d. h. die zum Springen organisirt sind, die genannten Theile vorzugsweise lang sind. Bei der Hand dagegen, bei wclchor es weni- 

ger auf kriftige, al auf schnelle Bewegung ankommt, wird letztere auch bei verhältnissmässiger Kürze der Handwurzel erzielt, und deshalb treten hier die Hauptwerkzeuge des Erfussens, die Finger, stïker hervor; wir sehen daher auch an Thieren, diss jemehr die vordere Extremität zum Erfassen bestimmt ist, desto mehr die Zehenglieder hervortreten, jemehr dagegen diesellie nur zum Gehen dienen, mithin eben das lurch Beugung hervorbringen soll, was die hintre Extremität dureh Streckung erzielt, desto mehr der Carpus und Metacarpus das Uebergewicht bekommen.

Wenden wir nun unsern Blick auf die Muskulatur der Extremititten, so bemerken wir zunächst, dass bei den untern Gliedmassen des Menschen dic Strecknuskeln offenbar das Uebergewicht über die Beugemuskeln haben. Der m. rectus femoris, vastus externus und internus, cruralis und subcrureus, welche das Knie strecken, sind mindestens loppelt so stark als der m. senitendinosus, scmimembranosus, biceps und popliteus, welche dasselbe beugen. Noch augenfalliger wird dies aber an dem Fusse: während die Flexoren, der m. tibialis anticus und peronaeus tertius, ihre mindestens gleichstarken Antagonisten an iem m. tibialis posticus und peronaeus longus und brevis finden, kommen noch als Extensoren die starken Wadenmuskeln, der m. gastrocnemius, soleus und plantaris hinzu, welche, wic erwähnt, dadurch ungemein an Kraft gewinnen, 

dass sie sích durch den Fersenhöcker verhältnissmässig weit von dem Gelenke ansetzen. Nicht so iiberwiegend ist die Streckung bei den Zehengliedern, welche sich überhaupt bei der Extension des ganzen Gliedes mehr indifferent verhalten; indessen muss es uns doch auch bei ihnen auffallen, dass es am Fusse ebenso xwei mm. extensores communes digitorum als flexores giebt, withrend an der Hand den dreifachen flexor communis nur ein einfacher extensor entgegenwirkt. Was hier von dem Menschen gesngt ist, gilt zum Theil noch in höherem Grade auch von den Thieren.

An den obern Extremitäten des Menschen sind zuförderst Benger und Strecker des Vorlerarms ziemlich gleich entwickelt, indem der $\mathrm{m}$. biceps und brachialis internus durch den m. supinator longus und pronator teres unterstũtzt ihren Antagonisten, den vier Anconäien, diss Gleichgewicht halten; indessen ist nicht zu übersehen, dass bei Indiviluen, die ihre Armmuskeln durch Uebung gest:irkt haben, gerade die Beuger am kräftigsten hervortreten. Bei den Thieren aber finden wir die Beuger durchgehends stärker, so namentlich auch bei den Affen, bei denen dadurch der Oberarm ein seitlich zusammengedrücktes, von vorne nach hinten breites Aussehn erhält. - An dem Handgelenke haben schon beim Menschen die Beuger ein offenbares Uebergewicht, da der m. flexor carpi radialis und ulnaris den extensoribus radialibus et ulnari 
schon gleich sind, aber len m. palmaris longus noch zu Hülfe bekommen, der das Eigenthiimliche hat, lass er allein die Hanl in ganz gerader Richtung flectirt; bei den Thieren wird nun aber das Uebergewicht der Beuger noch dadurch sehr vermehrt, lass bei ihnen das os pisiforme weit nach hinten tritt, und dem m. flexor ulnaris auf gleiche Weise zu der von dem Gelenke entfernten Insertion dient, wie das tuber calcanei den Wadenmuskeln. An den Fingern endlich ist bei Menschen wie bei Thieren die Beugung unbestreitbar vorherrschend, da einem einzigen nicht sehr starken $m$, extensor communis digitorum ein starker oberflichlicher und ein eben solcher tiefer Flexor, und ausserilem noch die I.umbricalmuskeln entgegentreten.

Sonach ist also auch aus der Muskulatur ersichtlich, dass bei den untern Extremititen Strekkung, bei den obern Beugung vorherrschend ist, und zwar letzteres bei Thiven in viel höherem Gralle als beiu Menschen.

Gehen wir nun in der Vergleichung der Anordnung der Muskeln an der obern und untern lixtremitit des Menschen weiter, so finden wir:

I. dass der untern Extremität diejenigen Muskelı ganz abgehen, welche bei der obern die Pround Supination lowirken;

2. Inss die Extensoren und Flexoren der Hand, wenn sie einseitig wirken, Adduction oder Abduction derselben erziclen, während dic ho- 

mologen Muskeln des busses nur eine geringe Seitwärtsdrehung der Fusssohle bewirken können;

3. dass lie einzelnen Finger freiere Beweglichkeit besitzen als dic Zehen.

Nur auf den letzteren Punkt müssen wir hier noch näher eingehen.

Gewiss mit Recht kann man die Hand ein eigenes selbststindiges Organ nennen; sic hat sich gewissermassen von dem übrigen Organismus frei gemacht, während der Fuss ein integrirender Theil der Extremitit geblieben ist. Dies beruht nicht etwa blos auf der weniger eingeschränkten Gelenkverbindung an ler Hand, sondern lisst sich auch in deren ganzer morphologischer Bildung nachweisen. In den Extremititen ist durchaus die Längenrichtung und der Parallelismus vorherrschend; die Knochen derselben gehören zu den Röhrenknochen, und hängen mit ihren äussersten Enden zusammen; wo ein Theil aus mehr als einem. Knochen. bestcht, da liegen diese parallel neben einander. Dieselbe Bildung findet sich auch an dem Fusse: die Fusswurzelknochen sind in Allgemeinen in die länge gezogell, und liegen einander parallel; von ihnen gehen in ganz geraler Richtung die einander parallelen Mittelfussknochen, und von diesen ebenso wieder die 'Zehenglieder nach vorne ab. So ist also an dem Fusse wic an der übrigen Extremität ein Parallelismus nicht zu verkennen. Anders ist es mit 



\section{$-93$}

der Hand. Den schmalsten Theil dersellien machen die Knochen der Handwurzel aus, welche zur ersten Peihe zusammentreten, an diese schliesst sich die schon mehr in die Breite ausgedehnte zweite Reihe der Handwurzelknochen an; von dieser endlich gehen die Mittelhandknochen mit ihren Fingergliedern divergirend nach vorn, indem namentlich der des Daumens seine Gelenkfläche nicht wie die grosse Zehe gerade nach vorne, sondern seitlich nach innen hat. So ist also eine strahlige Richtung in dem Knochenbaue der Hand zu erkennen. Diese Ausstrahlung ist nun noch dentlicher in fler Muskulatur ausgesprochen, denn die von dem Arme her zu den Fingern gehenden Muskeln werden fast ohne Ausnahme in der Mitte der Handwurzel z.nsammengehalten, um von da aus zu den zugchörigen Fingern hinzulaufen, ja sogar die in der Hand selbst entspringenden kurzen Muskeln des Daumens und des kleinen Fingers nehmen ihren Ursprung grössten Theils von diesem Punkte, namentlich von dem ligamentum carpi volare proprium, und gehen von diesem divergirend ab. An dcm Fusse dagergen behalten auch die Muskeln die parallele Riehtung bei, welehe an der Extremität vorherrschend ist, denn die zu den Zchen gehenden langen Muskcin gelangen nicht unter oder über, 'sondern neben den Fusswurzelknochen der ersten Reihe hingehend \%u dem Orte ihrer Bestimmung, und die kurzen Muskeln entspringen nicht sowohl aus der Mitte, als 



\section{$-94$}

vielmehr von lem ihrer Zehe zunüchst fiegenden Ḱnochen der Fussivurzel.

Für liese grössere Selhststänligkeit und Unabhängigkeit der Hand spricht ferner der Umstand, lass sie eine eigene, von dem Schwerpunkte des Kïrpers ganz unahbingige Axe besitzt, auf welche sich die Bewegung ihrer Fingerglieder fast durchgehends bezieht. Diese Axe nämlich wird von dem Mittelfinger bezcichnet, welcher an der Hand am weitesten hervorragt, während die übrigen Finger nach beiden Seiten hin an Liinge abnehmen, und auf liesen ist ausser der allgemeinen Beugung und Streckung alle Bewegung der Finger zy beriehen. Der Daumen und der kleine Finger besitzen gewisse eigene Muskeln, welche wir Abductoren nennen; mit diesen von ganz gleicher Wirkung für die übrigen Finger sind die sogenannten mm. interossei externi, welche wir deshalb auch Abductoren nennen könneı. Diese sïummtlichen Abluctoren nun haben eine solche Anordnung, dass sie bei gemeinsamer Wirkung die Finger spreizen, d, h. alle von dem unbeweglich bleibenden Mittelfinger abzichen. Diesen Muskeln antagonistisch sind ler m. alductor pollicis und die mm. interossei interni als Adductoren so angeordnet, dass sie bei geineinschaftlicher Wirkung die Finger schliessen, d. h, alle gegen den mit keinem solchen Muskel versehenen Mittelfinger hinziehen. Von diesem Adduciren scheint mir ferner die Wirkung des m. opponens pollicis und digiti 

minimi nicht wesentlich verschieden, denn das Entgegenstellen orler Opponiren lässt sich so erklïren: dass der Daumen und der kleine Finger, durch den Zeigefinger und den Ringfinger an einem unmittelbaren seitlichen Anscḱliessen an den Mittelfinger gehindert; liese beiden Finger zu umgehen suchen, und num von vorn her sich dem Mittelfinger nähern. - Ganz anders verhält es sich mit dem Fusse, demsellen gehen nicht allein die musculi opponentes ganz ah, sonilern es haben auch die nm. interossei interni und extemi ihre Bezichung nicht auf die mittlore Zehe, sondern auf die innere oder grosse, indem sie als Aluluctoren stimmtliche Zehen nach aussen, als Adductoren die vier "̈ussern Zehen nach innen, gegen die grosse Zehe hinziehen. Es wird hier bemerklich sein, dass ich den sogennnnten ersten ausseren Zwischenknochenmuskel seiner Wirkung wegen unter die inneren rechne, wozu ich mich so eher berechtigt halte;" da dieser Muskel nicht, wie es sonst bei den aussern Z Zwischenknochenmuskeln der. Fall ist, von zwei verschiedenen Mittelfussknochen entspringt. Bemerken wir nun noch, dass an dem Fusse nicht die nittlere Zehe, sonilem die erste oder die zweite die längste ist (gewöhnlich giebt man die zweite als die lingste an, ich glaube aber dass dies meistens nur von einer schiefen Stellung der ersten herrïhrt, denn bei gan\% normalgebildeten Füssen, naınentlich von Kindern, fand ich in der Regel die erste am weitesten nach 
vorn reichen) und lic übrigen nach aussen hin an Lïnge immer nuehr abnchmen, so werden wir uns wohl geneigt fühlen, dieses offenbare Vorherrschen der inneren Zehen mit der Lage der allgemeinen Körperaxe in Bezichung zu bringen, indem nämlich der möglichst zu unterstützende Schwerpunkt bei dem aufrechtstehenden Menschen gerade mitten zwischen dic beiden Füsse zu liegen komnit. - Dieser Unterschied zwischen Hand und Fuss finlet sich nun bei den vierfüssigen Thieren nicht, da bei ihnen theils an beiden Glicimassen der Parallelismus vorherrschend ist, theils auch fast immer die beiden seitlichen Zchen kïrzer, dagegen die mittlercn ziemlich gleich lang sinl, was vielleicht ladurch zu erklïren wire, lass der Schwerpunkt les Körpers bei ihnen nicht zwischen je zwei, sonlern in der Mitte rwischen allen vicr Extremitaiten zu liegen konmt.

Was endlich noch die Verschiedenheit zwischen Hand und Fuss des Menschen hinsichtlich des Grales der Beweglichkeit der einzelnen Finger und Zehen betrifft, so ist zu bemerken, Inss die erstere in Vortheile ist, weil zuförderst die gemeinsamen Beuger und Strecker bei ihr mehr als an dem Fusse in einzelne Biuche getrennt sind; weil ferner der m. extensor pollicis brevis, abluctor pollicis longus und extensor indicis theils mehr separirt, theils mehr entwickelt sind als die ihre Funktion verrichtenden Muskeln au Fusse; und weil endlich der m. 
opponens pollicis und digiti minimi, und der m. extensor digiti minimi proprius gar nicht lhresgleichen an dem Fusse haben.

Nach obiger Vergleichung des organischen Baues der menschlichen Hand und des menschlichen Fusses würden sich die charakteristischen Merkmale der Hand in folgenden Punkten aufstellen lassen:

1. Bewegliche Verbindung der beiden Knochen des Vorlerarms, und Anwesenheit von Muskeln, welche durch Drehung des einen von diesen Pro- und Supination bewirken.

2. Verbindung mehrerer Handwurzelknochen als Gelenkkopf mit einer nur durch den beweglicheren Knochen des Vorderarms gelildeten flachen Gelenkgrube, und dadurch möglichste Freiheit in diesem Gelenke.

3. Geradliniges Abgehen der Hand von den Vorderarme, und dadurch, sowie durch die Muskelbildnng ziemlich gleichmiässige Entwicklung der Beugung und Streckung.

4. Breite und Kürze der Handivurzel, und Vermögen, die Wölbung derselben bis zum Hohlmachen der Hand zu steigern.

5. Strahlige Bildung in dem Knochenbaue und der Muskulatur.

6 Vermögen des Daumens und des klainen Fingers, sich den übrigen entgegenzustellen.

7. Verhältnissmüssig vorherrschende Länge der Fingerglieder. 

8. Grössere selbstatïndige Beweglichkeit dèr einzelnen Finger.

Nachilem wir so die charakteristischen Merknıale der menschliehen Hand festgestellt haben, wirl es uns leicht, mit Beziehung anf die gegebene Beschreibung der Muskeln des Affen, und mit Berïcksichtigung seines Knochenbaues, darzuthun, dass die sogenannten Hände des Affen der menschlichen Hand durchaus nicht gleichzuachten sind.

Betrachten wir zunïchst die hinteren' Gliedmassen des Affen, so finden wir an ihnen, wie bei dem menschlichen Unterschenkel eine Tibia und Fibula fast ganz unheweglich mit einander verbunden, und durchaus keine Spur von Muskeln dẹr Pro- und Supination; ferner einen von beiden genannten Knochen eingeschlossenen Talus, und daher nur in einer Ebene mögliche Gelenkbewegung; ferner einen wie hei len Menschen stark nach hinten hervorstehenden Calcaneus, an den sich die Wadenmuskeln, den menschlichen uhnlich ansetzen, und daher deutliches Vorherrschen der Streckung; ferner Bildung und Verbindung der Fusswurzelknochen ganz denen des Menschen ïhnlich, vorherrschende Längenausdehnung und Unvermögen durch seitliche Verschiebung eine Höhlung zu bilden; ferner vorherrschenden Parallelismus in der Knochenbildung und dem Muskelverlaufe des ganzen Gliedes; endlich keine Spur von opponirenden Muskeln des Daumens und des kleinen Fingers. 

Hiernach gehen also die sechs zuerst genannten charakteristischen Merkmale der Hand den hinteren Gliedmassen des Affen ganz ab, und es bliebe nur noch die grössere Lünge der Fingerglieder, und die freiere und selbststöndigere Beweglichkeit vier einzelnen Finger übrig. Von/diesen ist nun allerdings erstere insofern begriindet, als bei den Aften die drei Theile des Fusses - Fusswurzel, Mittelfuss und phalanges digitorum - ziemlich von gleicher l.ingenausdehnung sind; die letztere dagegen ist nur scheinbar, durch die verhältnissnïissig grössere Läinge der Zehenglieder hervorgebracht. Nur das Spreizen der Zehen ist bei den Affen behufs des Festhidtens auf den Bäumen mehr entwickelt als bei dem menschlichen Fusse, deun nicht allein dass bei ersteren die $\mathrm{mm}$. interossei (XVI. No. 7, 9) die Einrichtung der gleichnamigen Muskeln an der menschlichen Hand zeigen, mithin besser zum Spreizen und Schliessen der Zehen geeignet sind, als die an dem menschlichen Fusse, so geht auch bei ihnen von dem n. tibialis inticus (XV. No. 1) ein zweiter Kopf ab, der an der innern Seite der grossen Zehe inserirend als in. abductor hallucis longus erscheint, und der m. peronaeus tertius (XV. No. 5) geht so an die äussere Fläche der fünften Zehe, diss er als ein $\mathrm{m}$. aluductor digiti quinti longus angesehen werden muss, welche beide der menschliche Fuss nicht aufuweisen hat. Dagegen ist selbstatindige Beugung und Streckung der einzelnen Zehen bei den 



\section{$-100$}

Affen noch eingeschriinkter als an dem menschlichen Fusse, denn bei jenen spaltet sich erstens die Sehne des m. extensor digitorum communis (XV. No. 3) erst auf dem Rüicken des Fusses, so dass die vier kleineren Zehen immer zugleich gestreckt werden miissen; es geht zweitens die Sehne des m. flexor hallucis longus (XV. No, 12) nicht allein an die grosse, sondern auch an mehrere andere Zehen, und ist dabei so mit der des $\mathrm{m}$. flexor digitorum communis longus ( XV. No. 11 ) verbunden, dass auch die Beugung aller Zehen gemeinschaftlich sein muss; und es sind endlich Jrittens die flectirenden, abducirenden und adducirenden Muskeln der grossen und der kleinen Zche viel enger unter einander verschmolzen als bei dem Menschen.

Dic vordern Gliedmassen der Affen nü̈ssen nothwendig mehr Aehnlichkeit mit der menschlichen Hand haben, aber es werden sich doch auch an ihnen wesentliche Verschiedenheiten leicht herausstellen.

Der Vorderarm des Affen hat ebenso wie der des Menschen einen beweglichen Radius, aber derselbe steht mit seinem oberen Ende nicht so wie bei diesem neben der Ulua nach aussen, sondern mehr vor derselben. Dadurch wird die Rotation desselben so eingeschrănkt, dass die Supination nur halb so weit ausgeführt werden kann als bei dem Manschen; der Affe kann die Hohlhand nicht ganz nach vorn kehren und den Daumen nieht ganz nach aussen halten, sondern letztere nur nach vorn, er- 
stere nur nach innen bringen, es sei denn dass das Schultergelenk zu Hülfe küme.

An dem Handgelenke des Affen ist zu bemerken, dass theils die Ulna etwas mehr zur Verbindung beiträgt als bei dem Menschen; ganz besonders aber, dass das os pisiforme ganz aus der ersten Reihe der Handwurzelknochen heraus nach hinten getreten ist, daselbst nach Art des Fersenhöckers hervorragend dem m. flexor ulnaris (XV. No, 1) zur Insertion dient, und dass mithin hier die Beugung ler Hand das Uebergewicht ïher die Streckung bekommt.

Die Handwurzelknochen des Affen sind denen des Menschen ähnlich, aber mehr lang als breit; die ganze Hand bekommt dadurch bei ihm ein schmilleres und mehr in die Länge gezogenes Aussehen, und ist zomm Hohlmachen deshillb weniger geeignet. Vou der Handwurzel gehen die Mittelhandknochen, welche verháltnissntissig lang sind, in ganz gerader, nicht we bei dem Menschen divergirender Richtung ab, so dass jener strahlige Bau bei der Hand des Affen weniger hervortritt als bei dem Menschen." Die Finger des Aften sind hinsichtlich der Läingo denen des Menschen ziemlich gleich, mit Ausnahme des Dallmens; dieser ist im Allgemeinen bedeutend kïrzer, und hat sogar bei einigen Affenarten nur ein Glied, deshalb ist auch sein Vermögen, sich den ülrigen Fingern entgegen zu stellen, geringer als bei dem Menschen; deun bei diesent kënnen dic gestreckten Finger nit iliren Spitzen die des opponirten Dall- 
mens berihren, bei den Affen alser kann dies nur mit gebogenen Fingern geschehen.

Was die Bewegung der Finger betrifft, so zeigt es sich, dass deren Abuluction und Adduction bei dem Affen eben so wie bei dem Menschen entwikkelt ist; lass aber die einzelnen Fingern des ersteren bei weitem weniger selbstständige Beweglichkeit besitzen, vielmehr Beugung und Streckung immer gemeinschaftlich ausführen müssen, denn: der m. flexor brevis ligiti minimi und der m. extensor pollicis brevis fehlen dem Affen gïnzlich; der m. flexor pollicis brevis (IX. No. 3) ist mit den m. adductor pollicis zu einem Muskel verschmolzen; der m. flexor pollicis longus (VIII. No. 7.) ist nur ein Theil des m. flexor digitorum communis profundus; der m. extensor digiti quinti (VIII. No. 12) giebt auch eine Sehne an den vierten Finger; der m. extensor pollicis longus und der m. extensor indicis (VIII. No. 13) endlich sind mit einander verschmolzen, und ge len eine dritte Sehne an den Mittelfinger.

Aus diesem allen geht hervor, dass die sogenannte vordere Hanil des Affen sich von der litenschlichen Hand dadurch unterscheidet; dass:

I. bei ihr die Supination nur unvollkommen ist, 2. die Flexion mehr als die Extension entwik. kelt ist,

3. das Vermögen, zu unfassen geringer ist;

4. das Opponiren des Daumens weniger bedeutend, und 



\section{$-103$}

5. die selbstständige Beweglichkeit der einzelnen Finger beschränkter ist.

Es liesse sich nun wohl noch nachweisen, dass die menschliche Hand auch als Tastorgan den Vorrang vor ier des Affen einnimmt; indessen genügt schon das Gesagte um zu beweisen: lass sowohl die vordern als die hintern sogenannten Hinde der Affen diese Benennung niclit verdienen, sondern nichts anderes sind, als zum Erfassen mässig dicker Gegenstïnde, namentlich der Baumäste, organisirte Füsse.

\section{E. Burdach.}






AMNH LIBRARY 